\title{
Housing, Health, and Ageing in Texas Colonias and Informal Subdivisions
}

\author{
Francisca Bogolasky1, Peter M. Ward ${ }^{2 *}$ \\ ${ }^{1}$ LBJ School of Public Affairs, University of Texas at Austin, Austin, USA \\ ${ }^{2}$ Department of Sociology and LBJ School of Public Affairs, University of Texas at Austin, Austin, USA \\ Email: *peter.ward@austin.utexas.edu, fbogolasky@utexas.edu
}

How to cite this paper: Bogolasky, F., \& Ward, P. M. (2018). Housing, Health, and Ageing in Texas Colonias and Informal Subdivisions. Current Urban Studies, 6, 70-101.

https://doi.org/10.4236/cus.2018.61004

Received: December 24, 2017

Accepted: March 9, 2018

Published: March 12, 2018

Copyright (C) 2018 by authors and Scientific Research Publishing Inc. This work is licensed under the Creative Commons Attribution International License (CC BY 4.0).

http://creativecommons.org/licenses/by/4.0/

(c) (i) Open Access

\begin{abstract}
Literature on housing and health outcomes among the elderly generally covers issues such as the relationship between housing quality and health; the intersection between place and space at different stages in the life course; and the impact of public policy to mitigate negative morbidity and mental health outcomes. However, there is little research about the ways in which certain types of informally developed neighborhoods such as colonias and informal homestead subdivisions offer micro-level spaces and housing arrangements that are conducive to family building, household extension, and care for aging parents, but which also have negative outcomes especially for the elderly by exacerbating certain chronic health problems and impaired mobility. In short, space and place matters. This paper provides an overview of the literature on the intersection between housing and health, and drawing upon Texas survey data we explore how low-income (largely) Hispanic households access home ownership through informal homesteading and self-help in two informal subdivisions in Central Texas. Viewed across the life course, this colonia-type housing is associated with a number of particular negative health and mobility impacts especially among the elderly, while at the same time providing an affordable and socially embedded residential alternative of living through old age.
\end{abstract}

\section{Keywords}

Housing, Health, Elderly, Colonias, Self-Help, Texas

\section{Introduction: Self-Help Housing in Texas and the USA}

In this paper we have two aims: first to review the general literature about the intersections between housing and health; and second, to drill down and explore the links between health and housing in a particular context of low-income pop- 
ulations who live in self-built or self-managed dwelling environments in informal settlements in Texas. In this first section we offer an overview of the latter since these will be unfamiliar to most readers. Called colonias along in the Texas-Mexico border, and informal homestead subdivisions elsewhere, these largely Mexican-origin populations live in unincorporated settlements located in the rural fringe beyond the city limits that have been the focus of multiple studies in the past two decades. These studies have described the large scale and nature of housing conditions found in colonias from multiple perspectives (inter alia): developer strategies and seller financing, property titling and insecurity, the lack or low levels of services and infrastructure, the nature of progressive home building and housing improvements over time, household organization across the life course, and the impact of public policy interventions especially in the 1990s (Davies \& Holz, 1992; Ward, 1999; Ward \& Carew, 2001; Texas Attorney General, 2014; TWDB, 1995; Donelson \& Esparza, 2010; Wilson \& Menzies, 1997; Olmedo \& Ward, 2016). Almost unknown, however, are the ways in which such self-building and colonia-type residence impact upon health. Within this relationship between informal housing and health, a particularly interesting issue, which we start to explore in this paper, is how it affects elderly populations and how this type of residence affects morbidity across the life course. These homes often provide the only viable dwelling environment to obtain home ownership in which low income parents raise their children to adulthood before they leave the proverbial "nest"; and thereafter continue to reside in these same homes as they enter middle and old age. Unlike better-off middle-income households, owners in colonia populations show relatively low mobility, and de facto, for many "a home is forever" (Gilbert, 1999; Ward, 2012).

Platted by developers in the 1970s and 1980s, much of the early policy concerns (late 1980s) about colonias focused both upon the appalling housing conditions as well as the extreme health hazards associated with low income settlements that had little or no services of water, drainage, power supply, etc. Rates of Shigellosis and Hepatitis A were twice that of the national average, occasional Cholera outbreaks occurred, and Gastroenteritis and respiratory disease were rife (Ward, 1999; Anders et al., 2008; Anders et al., 2010; TWDB, 1995). Moreover, health problems were exacerbated by the relative isolation of colonias to health care providers and institutions.

State intervention and legislation to improve and extend infrastructure to colonias from the early and mid-1990s onwards began to alleviate some of the exposure to these health hazards and extreme housing conditions, most notably through providing access to water supplies, regulating drainage and septic fields, by providing some levels of consumer protection to would-be home owners, and by limiting the development of new colonias - at least in the border region (Ward, 1999). In 2006, Senate Bill 827 established a three-level color-coded classification to identify colonias exposed to severe public health risks throughout the six Texas counties with the largest colonia populations, all located along the 
border. "Red" colonias are those that pose the greatest health and safety risks because they lack piped water and wastewater disposal; "yellow" colonias are those with adequate water and wastewater systems but which, due to a lack of road paving, drainage, or solid waste disposal, still pose certain health risks; and "green" colonias being those with adequate infrastructure that pose minimal health and safety risks (Durst \& Zhang, 2013; Durst \& Ward, 2014; Mier et al., 2008).

From the outset, these poor health conditions were the trigger for state intervention in order to legislate against the further growth of colonias, and to undertake concerted action to bring basic infrastructure into these poor peri-urban neighborhoods which, as in Mexico and elsewhere in Latin America, for very low-income workers represented the only viable route to home ownership (Davies \& Holz, 1992; Ward, 1999). While such legislation was largely successful in preventing further growth of the number of colonias (which levelled out at around 1500), the total colonia population in the border continued to increase through infill of formerly unoccupied or unsold lots, and through household increase as pioneer self-builders raised their families and today number around half a million, largely in six border counties. Studies have shown that while housing conditions in colonias were often abysmal at the outset, despite their very low incomes (of around $\$ 15,000$ per year household), many households were successful in upgrading their dwelling environment over 10 - 15 years, especially once they finally gained formal title to their properties (Durst \& Ward, 2014). In 1991, after the prohibition upon new colonia development, so called "Model Subdivisions" (MSRs-developer-led platted land with basic services of water, septic and street paving) took over from where colonias had left off (Durst, 2016), but recent evidence suggests that although those who contract-into an MSR and have services to their lots from the outset (unlike their earlier colonia counterparts), the added costs reduces their capacity to self-build and improve their home environment to an acceptable or modest standard, such that paradoxically some of the worst housing conditions observed in Texas today are found in these "model" subdivisions (Durst \& Ward, 2016).

The phenomenon of colonia type informal homesteading is not solely one of the border regions (Donelson \& Esparza, 2010; Ward \& Peters, 2007; Durst, 2017; Wiese, 2005). Informal subdivisions abound outside of many cities in the interior of Texas, as would-be home owners who cannot afford or are ineligible for formal financing, acquire lots in informal developer (seller) financed subdivisions. While households are not quite so poor as in the border (annual $\$ 20,000$ - 25,000 per household is the norm), they remain largely Hispanic, and follow similar self-managed strategies as their border counterparts, although actual self-help building is less commonplace, with manufactured homes being more usual (as in Figure 1), although self-built additions such as ramps, porches, shade roofs, carports, etc., are regular features (see subsequent figures). 


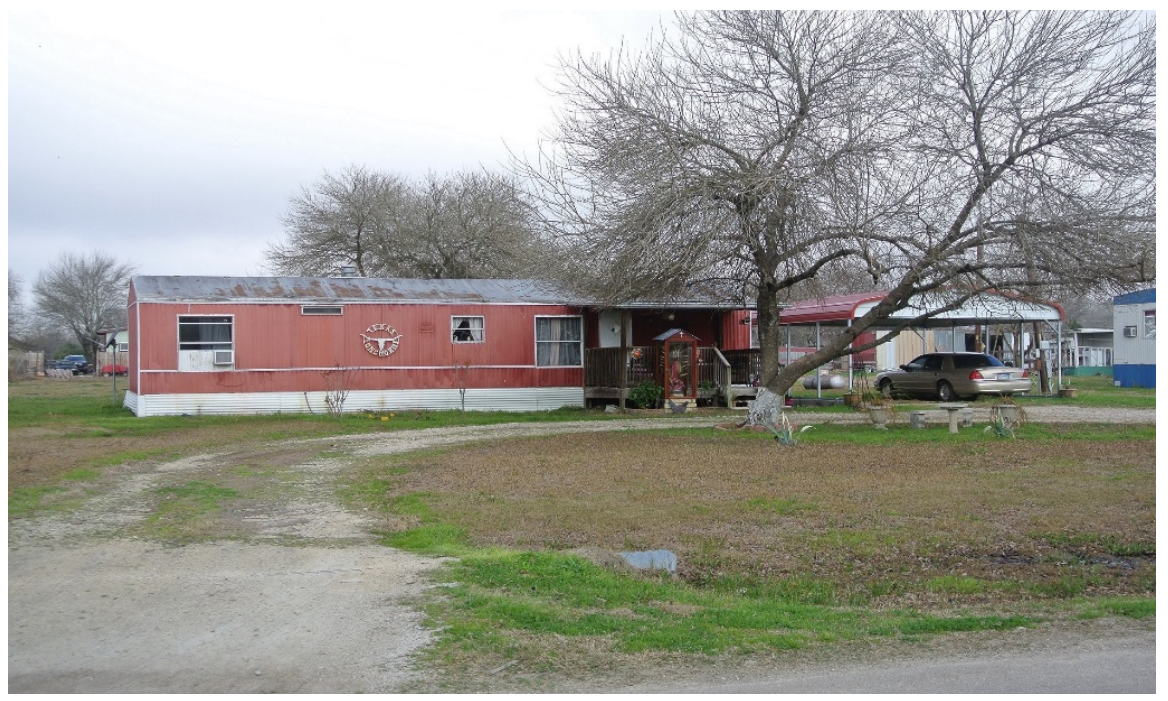

Figure 1. Typical single-wide manufactured home (trailer) with "skirt" around the wheelbase. Rancho Vista. Author's photo (Ward).

As policy makers had intended, the early legislation and intervention described above had a significant effect in reducing disease outbreaks, although we strongly suspect that colonia-type environments continue to show higher prevalence of disease and morbidity (Mier et al., 2008). One recent study points to this association by analyzing hospitalization by county for some 26 most significant diseases (Knab, 2016). In those counties where colonias are present, Knab (2016) finds significantly higher incidence of 19 of those 26 diseases, including Amebiasis, Brucellosis, Bacterial Food Poisoning, Shigellosis, Other Rickettsioses (non-tick-born), and Typhoid and Paratyphoid fevers, as compared to counties which do not contain colonias. While these data cannot link a causal relationship between colonia residence and a higher incidence of several of these diseases (given the obvious collinarity between being Hispanic, living in a border county, and being very low-income), the same author adopts a Bayesian statistical methodology to impute at the $97.5 \%$ level of confidence a link between several of these diseases and likely colonia residence.

In this paper we present an analysis in which we describe reported housing conditions and reported health issues, in order to analyze what specific elements of housing are perceived by residents as a threat to their health. We also start to explore how colonia and similar homesteading communities present both opportunities and challenges to households over the life course, and especially as owners age, become less mobile, and might be increasingly prone to infirmity. The peri-urban rural location, large-sized lots (half- to one-acre), and the flexibility of organizing and recasting residential space among family members during the life course(s), are likely to offer increasing opportunities for in-situ elderly parent care, especially among Mexican-origin first and second generation households with strong traditions of intra-household care for elderly parents, and relative incapacity to afford formal institutional residential care (Angel, An- 
gel, \& Hill, 2008).

In the following sections of the paper we first offer an extensive review of the wider literature on housing and health, especially in relation to ageing populations. Next, using local survey data from two informal settlements in Central Texas we examine the intersection between housing conditions and health and morbidity patterns in an effort to identify some of the endemic health and mobility challenges facing very low-income home owners (Corburn \& Riley, 2016; Sverdlik, 2011). Finally, we offer some preliminary thoughts about future research and thinking that may help us to better understand the ways in which informal housing practices can help to improve the quality of life and health scenarios among ageing residents in colonias and similar low-income subdivisions.

\section{Literature Review: Intersections between Housing and Health}

Before turning to our case study description and analysis, we offer an brief overview of the broader literature that explores some of the hypothesized intersections between housing and health including: housing structure and quality; economic and marital status; stage in the life course and the impacts of ageing; exposure to environmental and other risks and sources of infection and illness; and the significance of location and neighborhood characteristics.

For both developed and developing nations there is widespread consensus that housing quality/problems, impact health across the life course (Corburn \& Riley, 2016). As several authors describe, for more than a century society has recognized that improved housing generally leads to improved health (Jacobs et al., 2010). However, there is less consensus on the nature of the relationship. There is no clear view or solution regarding if, and how far, housing improvements can help to overcome health problems. The independent effect of poor housing on health remains largely unknown, due to the many confounding factors that could be affecting in this relationship (World Health Organization Europe, 2005). For some time, in the $19^{\text {th }}$ and early $20^{\text {th }}$ centuries, experiences in basic sanitation ventilation, reduced crowding and other improvements contributed to conquering epidemics such as typhoid and tuberculosis. Subsequently, other interventions such as improved sanitation and better food preservation were further linked to advances in public health. More recently, attention has shifted from communicable diseases to more chronic afflictions (such as asthma, cancer, lead poisoning, mental health and injuries, among others). Thus, connections between housing and these afflictions have been demonstrated, but the association is complex and can be influenced by several confounding variables (Jacobs et al., 2010).

That caveat stated, it seems clear that housing can affect health through a variety of components. Jacobs (2011) describes that in general, conditions in the physical dwelling contribute to adverse health effects in at least 5 broad categories: physical conditions (heat, cold, energy efficiency, light, ventilation, noise, 
etc.); chemical conditions (carbon monoxide and others); biological conditions (rodents, house dust mites, cockroaches, humidity and mold); building and equipment conditions and social conditions. In terms of housing quality, elements such as atmospheric conditions, supply of drinkable water, housing structure and construction quality, exposure to pests and disease, etc., can affect health in terms of infectious diseases, chronic illnesses, and susceptibility to injuries, poor nutrition and mental disorders, among others (Krieger \& Higgins, 2002). Second, there are elements that go beyond housing quality or structure that also appear to exert and independent effect upon health and wellbeing such as location, neighborhood and the nature of social networks (James III, 2008). Combined, these components (housing structure and quality and the social context of housing) can be related to residential satisfaction, itself connected to poor or good health, especially for the elderly population.

For example, Miles and Jacobs (2007), use logistic regressions based on household survey data from seven European cities to show the magnitude of the association between housing conditions and noise annoyance, and the exacerbation of asthma and related respiratory symptoms. They find that respondents across a range of cities who were strongly annoyed by general neighborhood noise, had twice the odds of a doctor-diagnosed asthma attack or related respiratory symptom than those not at all annoyed. Those strongly annoyed by traffic noise had $68 \%$ higher odds, while drainage problems at the housing unit were associated with $54 \%$ higher odds of experiencing respiratory symptoms, building structural problems with $27 \%$ higher odds, and a leaky roof with $35 \%$ higher odds.

In the same line, a 2010 review of evidence on the effectiveness of housing interventions that affect health outcomes (Krieger et al., 2010; Hevia, 2013), concluded that some interventions are effective in reducing exposure to indoor biologic agents that can cause asthma symptoms among people with asthma. In particular, sufficient evidence supports the dissemination of multifaceted, in-home, tailored interventions for asthma and combined elimination of moisture intrusion and leaks and removal of moldy items to reduce respiratory symptoms, among others. However, a limitation of these conclusions is that the effectiveness of interventions may vary by region (due to differences in climate and types of housing), and therefore these local conditions should be taken into account. Another relevant point is that these interventions will be limited in their ability to reduce these health issues if they are exposed to other elements. For asthma, for example, other indoor and outdoor pollutants, such as environmental tobacco smoke need to be considered.

Similar reviews of evidence have been undertaken for health outcomes associated with exposure to chemical agents, such as pesticides, lead and other elements (Sandel et al., 2010), and for housing interventions that affect safety and injury outcomes (Di Guiseppi et al., 2010). In both cases, the authors also find a subset of interventions where there is sufficient evidence to justify interventions, 
although in both cases they show again that such interventions are strongly influenced by contextual factors, local characteristics and population demographics. In a review of the scientific data on disparities in housing and associated health outcomes Jacobs (2011) shows evidence from a set of studies describing the adverse health consequences associated with living in highly segregated poor neighborhoods, such as body mass index and other diseases such as diabetes, chronic lung disease, hospitalizations for asthma and others.

Of course, the effects of housing on health are heterogeneous, since not all individuals receive or perceive the consequences of housing quality (or other characteristics of housing and neighborhood), in the same way. The main point here is that there are some specific groups (such as such as children, sick, elderly or unemployed), that are more likely to be vulnerable to poor housing, and who additionally are more likely to live in substandard housing and to spend longer periods of time indoors, thereby being exposed to potentially hazardous environments (Thomson et al., 2009).

\subsection{Ageing in Place}

During their active lives individuals spend more time out of the home than in it, but with the approach of old age the balance shifts increasingly in favor of the home (Gaymu, 2003). "For the elderly the home represents a safe environment, rich in memories, and acquires the role of refuge" (Gaymu, 2003: p. 201). This refuge function is reinforced with the onset of old age, which is accompanied by a contraction of the social network and the appearance of the first signs of the rising disabilities and reduced mobility which make individuals more vulnerable.

As mentioned above, there are two main dimensions in the relationship between housing and health for the elderly population: quality of housing and elements such as neighborhood and location that go beyond the structural elements of housing. Specifically for ageing populations, Evans et al. (2000), examine the association between damp housing and adult health in four English counties. They found that damp was associated with the majority of negative health outcomes but that being unable to regulate internal dwelling temperature and keep the home warm enough in winter was a more important explanatory variable since cold and damp housing are closely related; indeed, it seems likely that their results embrace both effects.

Similarly, other authors have explored the relationship between weather and housing quality, and the association with respiratory health. Blane and Bartley (2000) sought to understand whether there is a mismatch within Britain between climate severity and housing quality ("inverse housing law") and whether this mismatch is associated with respiratory health. The Evans et al. (2000) study used a cross-sectional observational design across Britain sampling 3023 male and 3694 females in a Health and Lifestyle Survey. On all relevant items they find a mismatch between climate severity and housing quality. Controlling for cigarette smokers, they show that lung function is associated with climate and 
housing and that the physical quality of the housing seems to be most important to respiratory health in areas with a harsh climate, suggesting the existence of an "inverse housing law" (less quality housing construction in more extreme climate regimes).

Other factors also appear to be important when exploring the relationship between housing and health for the elderly population, and residential satisfaction with one's neighborhood appears to be an important element in shaping health outcomes. Moreover, increasing age has been positively associated with residential satisfaction, and with life satisfaction as a whole, and it appears that elderly residents are generally less likely to consider moving out of their home and neighborhood (James III, 2008). Issues of residential satisfaction are particularly important for the elderly among whom significant dissatisfaction can create chronic stress, with concomitant mental and physical health effects. As a group, the elderly are more susceptible to the effects of negative residential environment conditions. Conversely, a favorable residential environment creates positive impacts upon the psychological well-being of elders (James III, 2008; Varley, 2008).

In that same study, using a multivariate regression and controlling for intervening socio demographic variables, James III (2008) explores how the levels and determinants of residential satisfaction among elderly tenants in apartment housing in the US differ from other people, and argues that the impact of different living environments may vary depending upon one's age. Specifically, he finds that overall housing satisfaction rises with age, but that the rate of satisfaction change appears to differ among housing types and tenures. Among those aged 40 - 49, rented apartment tenants had lower residential satisfaction than did either single-family tenancy or homeowners. However, among later-aged cohorts, satisfaction with rented housing and rented apartment housing rose at a higher rate than that of owned housing. At ages 70 - 79, apartment tenant satisfaction exceeded that of rented single-family homes. Finally, at ages 90 and above, rented apartment satisfaction was greater than satisfaction in either owned homes or rented single-family homes. It appears that among younger and middle-aged groups homeownership provides greater ability to control one's environment, specifically by having greater rights to modify one's home. However, this opportunity to make modifications also carries with it the responsibility of home maintenance. The performance of maintenance, cleaning, and yard work, may become more difficult in later years.

Thus there is an increasing risk that in older age the obligations of homeownership can become a burden. As advanced age limits mobility options, the presence of nearby neighborhood services becomes increasingly important as does neighborhood quality, both of which are likely to have a greater impact upon elderly residents' control of their environment and, hence, on their satisfaction (James III, 2008). This growing importance of the neighborhood among the elderly may also be due in part to reduced social contacts caused by retire- 
ment, limited mobility, or loss of friends and family members (Altergott, 1988; Oh, 2003). Such contacts are vital as elderly people with a poor social network are at increased risk of loneliness and dementia (James III, 2008). Weak social networks can also affect health indirectly, by preventing elders from seeking medical help when necessary. Low-income elderly, especially those who reside in public housing, are socially isolated and lacking informal networks of support (Hall Ellenbecker et al., 2002). Moreover, many elders experience barriers related to culture, language, and poverty that contribute to their underutilization of non-emergency health care services. Conversely, informal supports and services in the areas of health promotion and wellbeing encourage elders to be proactive in their care and can contribute to feelings of control and self-care efficacy both of which have been identified as a predictor of health for elders (Chipperfield, 1993).

Marital status also appears to be related to housing and health. Gaymu (2003) analyzed whether certain marital status was associated with better housing conditions. Using data from the Population Activities Unit (PAU) of the Economic Commission for Europe, they found that for any given marital status (and with very rare exceptions), people aged 60 years and over have larger dwellings than those under 60 s, while those aged 85 or over have smaller dwellings than the younger elderly and even than young adults. That study also showed that for any given marital status, people aged 60 years and over are invariably less comfortably housed than younger age groups, regardless of which criterion of amenities is being considered (possessing a toilet, hot running water, or a bathroom). It appears that the older one is on the generation scale, the lower the standard of amenities enjoyed.

Finally, there is greater tendency for the elderly to "age in place". Gaymu (2003) argues that, for cost-related reasons (institutional care is usually more expensive, except in cases of extreme dependence) and/or because this is the trend strongly favored by the elderly, there is a consensus that people appear to want to stay in their own homes as long as they are able. However, evidence shows that adult residence in general is not equipped or adapted to needs, and in particular to the increasing fragility of their health as they get older.

In summary, the literature highlights the intersections of physical housing quality (especially ability to manage temperature and internal climate); location of neighborhood and satisfaction with residence in the same; level of social networks and ability to maintain them and avoid isolation, all intersect with health status especially among the elderly. The elderly are less mobile physically, and often have limited ability or disposition to move out of their homes to another neighborhood. This is especially true for those without access and/or the means to afford formal residential care and assisted living residence. In the following section we will explore several of these dimensions in the context of Texas colonia-type neighborhoods focusing upon: housing quality and structure related to reported ailments and health status, neighborhood location and access to health 
care services, and physical mobility both outside and within the home.

\subsection{Hispanic Ageing and Health in the Southern USA}

Two major datasets have led to a number of studies that offer interesting health and morbidity panel data for Mexican and Mexican-American populations among the elderly and which are helpful backdrops to our study. First, in Mexico the Mexican Health and Aging Study (MHAS) contains panel data from 2001 for a representative sample of people born in 1951 or earlier, and which has been extended with follow up sampling for 2003, 2012 and 2015

(http://www.mhasweb.org). The second study is the Hispanic Established Population for Epidemiological Study of the Elderly (H-EPESE), comprising a multiple wave study on Mexican American populations aged 65 or over at the time of the baseline survey in 1993-94. However, neither of these databases, nor most other major surveys (including the US Census), provide detailed data about housing conditions that can be readily linked to epidemiological outcomes. Thus it is often difficult to analyze the ways in which impaired health and mobility may be associated to specific housing conditions and household residential arrangements.

That caveat stated, summarizing the two datasets as a backdrop to the analysis that follows we observe that according to the MHAS data elderly males and females in Mexico show lower rates of disease and other diagnoses which are explained in large part by their lower levels of insurance coverage and skilled medical attention. In Mexico there is little provision of formal residential care available to very low-income groups, but this is partially obviated by higher cultural traditions to care for elderly parents. In the USA across the five states included in the panel data of the H-EPESE, both immigrant and native born Mexico origin populations report more chronic conditions than do elderly Mexicans, but fewer symptoms of psychological distress. However, longer residence in the US is associated with higher body mass indices, and while there are more facilities for residential care (through Medicaid), access is affected by eligibility, and by cultural traditions surrounding care of the elderly parents.

The H-EPESE study provides important background data about Hispanic ageing and health for US born Hispanics and for different age cohorts of migrants to the US. Comparing Mexicans in Mexico with Hispanics in the five states with different levels and periods of exposure to the US, Hispanics have significantly higher levels of arthritis, diabetes and heart attacks (with higher rates among females than males for arthritis and diabetes but lower on the dimension of heart attacks). Mexican natives show lower on these dimensions, but much higher on hypertension, and have lower obesity rates (Angel, Angel, \& Hill, 2008). Mexicans report having higher rates of "problem drinking", but are less likely to be smokers than their H-EPESE counterparts. As we will observe below, arthritis and diabetes are especially prevalent among elderly residents of certain neighborhood and housing types such as colonias and informal sub- 
divisions.

\section{Housing and Health in Two Central Texas Informal Homestead Subdivisions}

Informal housing development that embodies self-building by low-income households in order to gain entry into home ownership outside of formal financing (mortgages, etc.) is commonplace in less developed countries-indeed large swathes of many cities and metropolitan areas in Latin America and other regions have their origin in illegal modes of land capture and ex-post servicing and so-called "regularization" of property titles (Gilbert \& Ward, 1985). Called favelas and loteamientos in Brazil, pueblos jovenes in Peru, colonias popuares in Mexico, barrios in Colombia and elsewhere, in the absence of low cost formal public and private housing production systems self-building and informal housing production are often the primary, and often the sole form of gaining a foothold as "owners" in the housing market, albeit informally (and often illegally), and without adequate infrastructure. Less well known, and often largely unrecognized by planners and public alike, is the fact that informal self-building and self-management of housing is also widespread in developed countries such as the USA, especially (but not exclusively) in the south, although here the process of land acquisition is usually legal through seller financing and Contract for Deed (Ward, 1999; Way, 2010, see also Mukhija, 2014; Wegmann, 2015). Harris (2017) describes various modes of informality, three of which are commonplace yet poorly understood in the USA, Canada and elsewhere ("latent informality"; "diffuse" and "embedded"); while "overt" and "dominant" informality pervade much urban development in the Global South, as described above.

In the context of housing and health in the USA, especially when thinking about colonia-type subdivisions, it is important to recognize two important elements: first, that housing production is self-built or self-provided and managed, and shows a trajectory of expansion and consolidation over time, much of which is synchronized with the family building and life course. In their 2014 paper Durst and Ward (2014), analyze infrastructure, home values and household expenditures in a number of colonias outside Rio Grande City in South Texas, and find that across a ten year period from 2000-10 the large majority of dwellings showed significant improvement and consolidation, although most owners considered their houses unfinished, and expected to continue adding extensions or making improvements. Second, whether as a result of choice or constraint, colonia home owners "age in place" and there is relatively low outward mobility of home owners, in part because of the long term "use-value" to the household (i.e. choice), and because market dysfunction makes it difficult for would-be buyers to obtain mortgage financing for existing owners to sell their home (constraint), thereby leveraging the value of the asset ("exchange value", see Ward, 2016). Once residence has been established on the lot, many household heads will remain in the home for 30 years or more, such that many of the earlier residents to 
colonias and subdivisions of the late 1980s and early 1990s are now entering late middle age (Durst \& Ward, 2014; Ward, Jiménez, \& Di Virgilio, 2014). Studying the characteristics of this population and their housing conditions will provide a preliminary analysis of the general links between housing and health described earlier.

Given the elements discussed above, this paper will explore two main questions:

- What perceived housing issues are most prevalent for people living in two Central Texas informal homestead subdivisions?

- To what extent are these housing issues associated with negative health outcomes?

\subsection{Household Survey of Self-Help and Self-Managed Housing in Redwood and Rancho Vista Informal Subdivisions}

Based on data from surveys led by one of us (Ward) at the University of Texas at Austin, we use descriptive analysis to explore these associations between perceived housing conditions in informal homestead subdivisions and perceived health. The data that we present below come from several surveys undertaken at the University of Texas at Austin LBJ School of Public Affairs into the nature of self-help housing improvement processes, from which we can begin to think about the possible interrelationship between the dwelling environment and health and physical mobility status. In this case we draw primarily upon a 2010 survey of Housing Conditions, Sustainability and Self-help in two informal homestead subdivisions in Guadalupe County, Central Texas (LBJ School of Public Affairs, 2010; see also http://www.lahn.utexas.org). The study was undertaken by the LBJ School through the Community Development Clinic of the UT Law School at the request of community residents who were interested in seeking funding for home and weatherization improvements from the 2009 American Reinvestment and Recovery Act.

The housing conditions and health problems in the Redwood and Rancho Vista subdivisions are the main focus of this paper, and are described more fully below. Given the close links and good relations that the UT-Austin Law School enjoyed with the community leaders with whom it had worked previously, it was felt that in these two adjacent neighborhoods a mail-out survey method, properly explained and primed to residents, could reasonably be expected to work. But as a failsafe, and in order to offer some triangulation about the relative effectiveness of each survey technique, we also conducted random face-to-face interviewer applied surveys with every 5th dwelling unit, dropping-off mail back surveys at the intervening lots. This provided a total of 133 completed questionnaires almost equally split across the two settlements. Seventy percent of these completed questionnaires were mail-backs, representing a $15 \%$ response rate-more than double the response achieved in several of the previous mail out surveys that we had previously conducted with low income Mexican-origin 
populations in colonias. The survey gathered information about household structure, access to housing, length of residence on site, housing type and construction, a rating of perceived housing problems, and self-reporting on health problems and personal mobility.

A central part of the survey was to analyze the housing problems as they were perceived and experienced by the residents themselves. The unit of analysis was the household, and survey participants were asked to rate 24 housing problems on an ordinal scale where: 1) was a constant or severe problem; 2) an occasional problem; 3) satisfactory or broadly okay; and 4), good, (i.e. not a problem). They were also allowed to answer "5) not relevant or no opinion". Additionally, respondents were asked in an open-ended question to list the five most severe problems in their homes. These ratings provided us with an inventory of the range of problems that residents face, as well as the severity of each problem.

\subsection{Demographic Data Profiles and Housing Conditions}

The two adjacent neighborhoods Redwood and Rancho Vista each have over 300 lots located on the edge of Guadalupe County, several miles south-east of San Marcos (some 30 miles south of Austin, in Central Texas). They form part of a patchwork of similar unincorporated informal subdivisions across surrounding counties of Caldwell, Hays, Bastrop and Travis (which contains Austin). Almost all are home owners having purchased the land without services from a developer financed mechanism called a Contract for Deed (Way, 2010), whereby the deed is issued only after the lot has been paid in full. The large proportion of the population are Hispanic (88\%) compared with $36 \%$ for the county at large, and most have very low levels of education (Table 1). Household size in the survey neighborhoods (combined) vary a little but are typically between two and five household members with relatively few outliers. The average size is 3.94 , almost matching exactly the 2000 Census average household size of 3.98 for Redwood CDP (Census Defined Place). Twenty-seven percent of households had only one (8\%) or two (19.2\%) members, and a further $15 \%$ had three members. These three categories almost certainly concentrate the more elderly households across our sample, $42 \%$ of whom were aged over 51 (Table 1). Fourteen percent of the lots contain two housing units, with most of the persons in the second home being close relations of the primary household's dwelling. Almost half (46\%) of the households have one member employed, with a further $30 \%$ having two members contributing to the household income, although in neither case did the survey record whether this was part or full time employment. Sixteen percent of households were not in paid employment-again these are most likely retired householders. Including benefits, one-third (33.3\%) reported a monthly household income of between $\$ 2000$ and $\$ 3000$ (only 6.5\% earned above $\$ 3 \mathrm{~K}$ ), almost another third (31.7\%) reported earnings between $\$ 1000$ and $\$ 2000$; while $28 \%$ stated a monthly household income at under $\$ 1000$.

Most are long term residents: $29.5 \%$ having lived in the neighborhood for over 
Table 1. Demographics, housing conditions \& infrastructure.

\begin{tabular}{|c|c|c|}
\hline \multirow{2}{*}{$\begin{array}{c}\text { Dimension/Item } \\
\text { Demographics (Parenthesis }=\text { Guadalupe County 2010) }\end{array}$} & \multicolumn{2}{|c|}{ Rancho Vista \& Redwood (N=133) } \\
\hline & $\%$ & $\mathrm{~N}$ \\
\hline Hispanic/Latino & $92 \%(36 \%)$ & 110 \\
\hline Median Household Annual Income & \multicolumn{2}{|c|}{$\$ 43,3003(\$ 61,300)$} \\
\hline Median appraised value of home, 2009 & \multicolumn{2}{|c|}{$\$ 53,200(\$ 61,300)$} \\
\hline Education $\left(<12^{\text {th }}\right.$ grade, no diploma $)$ & $43 \%(16 \%)$ & \\
\hline Age of Head of Household & & 132 \\
\hline $18-30$ & $10 \%$ & 14 \\
\hline $31-40$ & $17 \%$ & 22 \\
\hline $41-50$ & $31 \%$ & 41 \\
\hline $51-60$ & $25 \%$ & 33 \\
\hline Over 61 & $17 \%$ & 22 \\
\hline Housing Type/Structure & & 131 \\
\hline Manufactured home (trailer) & $68 \%(18 \%)$ & 89 \\
\hline Self-built on site & $14 \%$ & 18 \\
\hline Other (camper/RV, modular home, contractor built. & $18 \%$ & 24 \\
\hline Age of primary dwelling $($ median $=22.4)$ & & 114 \\
\hline $1-14$ years & $33.3 \%$ & 38 \\
\hline $15-29$ years & $40.4 \%$ & 46 \\
\hline $30+$ years & $26.3 \%$ & 30 \\
\hline Dwelling with additions/extensions to primary unit & $39.5 \%$ & 51 \\
\hline $\begin{array}{l}\text { Additional dwellings on lot used by household members } \\
\text { (usually overflow sleeping space or } 2^{\text {nd }} \text { home) }\end{array}$ & $25.6 \%$ & 30 \\
\hline Infrastructure & & 133 \\
\hline Drainage-septic tanks with constant or occasional problems reported & $49.6 \%$ & 66 \\
\hline Power source to home & & 131 \\
\hline Electric & $61 \%$ & 80 \\
\hline Electric and propane (tanks) & $32 \%$ & 42 \\
\hline Other (Propane (tanks), gas) & $7 \%$ & 9 \\
\hline Water heater source & & 129 \\
\hline Electric & $87 \%$ & 112 \\
\hline Gas & $8 \%$ & 10 \\
\hline Other (no heating, other) & $5 \%$ & 7 \\
\hline Water heater problems reported & $18.6 \%$ & 24 \\
\hline Air Conditioning in dwelling & & 132 \\
\hline Full AC (exclusive or in combination with another method) & $40.5 \%$ & 53 \\
\hline Partial AC (exclusive or in combination with another method) & $49 \%$ & 65 \\
\hline Ceiling or floor fans, breezeways or no cooling system & $10.8 \%$ & 14 \\
\hline Reported problems with AC & $34 \%$ & 45 \\
\hline No Garbage Service (drop off, burn, dump) & $41.6 \%$ & 52 \\
\hline
\end{tabular}

Source: LBJ School of Public Affairs. 2010. Housing Conditions, Sustainability and Self Help in Rancho Vista and Redwood Informal Homestead Subdivisions in Central Texas. Final Report and Database for the Community Residents and for the Community Development Clinic of the UT Law School. http://www.lahn.utexas.org/Texas\%20 Colonias/Texas Colonias2.html. Also US Census data for Redwood CDP (Census Defined Place); and US Census for Guadalupe County, Texas. 
20 years, $31.3 \%$ for 15 - 19 years, and only $19 \%$ for less than nine years. This emphasizes the relative population stability and the fact that this is a middle-aged and ageing population. Manufactured (trailer type) homes predominate (Table 1 and Figure 1 \& Figure 2), but as mentioned in the introduction, self-building entirely from scratch is far less common in central Texas than in border colonias, although many trailer homes have self-built DIY extensions and modifications (porches, carports, false roofing for shade-see Figures 1-4).

Manufactured homes predominate (69\%), these being units that are built off site and moved onto the lot. They are usually trailers and may be single or double-wide (Table 1). They all share the feature of being on a wheel-base chassis

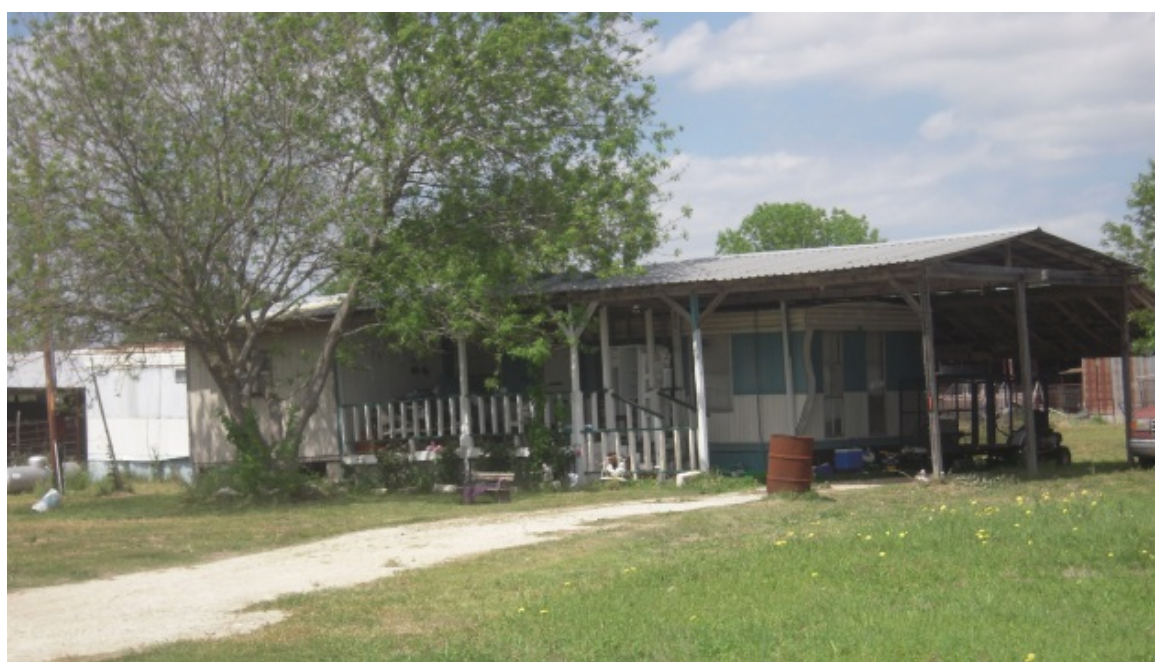

Figure 2. Older style manufactured trailer homes with self-built extensions, porch and false roof shade (Rancho Vista). Author's photo (Ward).

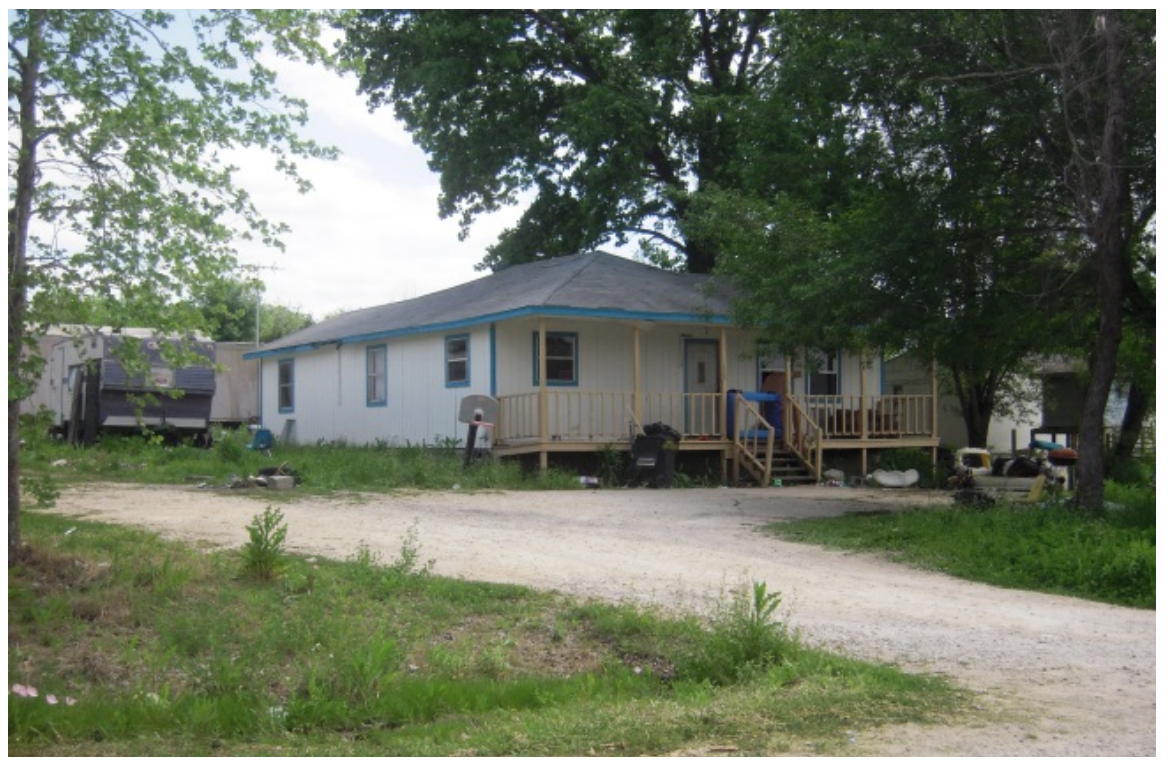

Figure 3. Self-built/modular home in Rancho Vista. (Note "camper/RV" alongside home extensions at rear, and "new" verandah at front”.) Author's photo (Ward). 


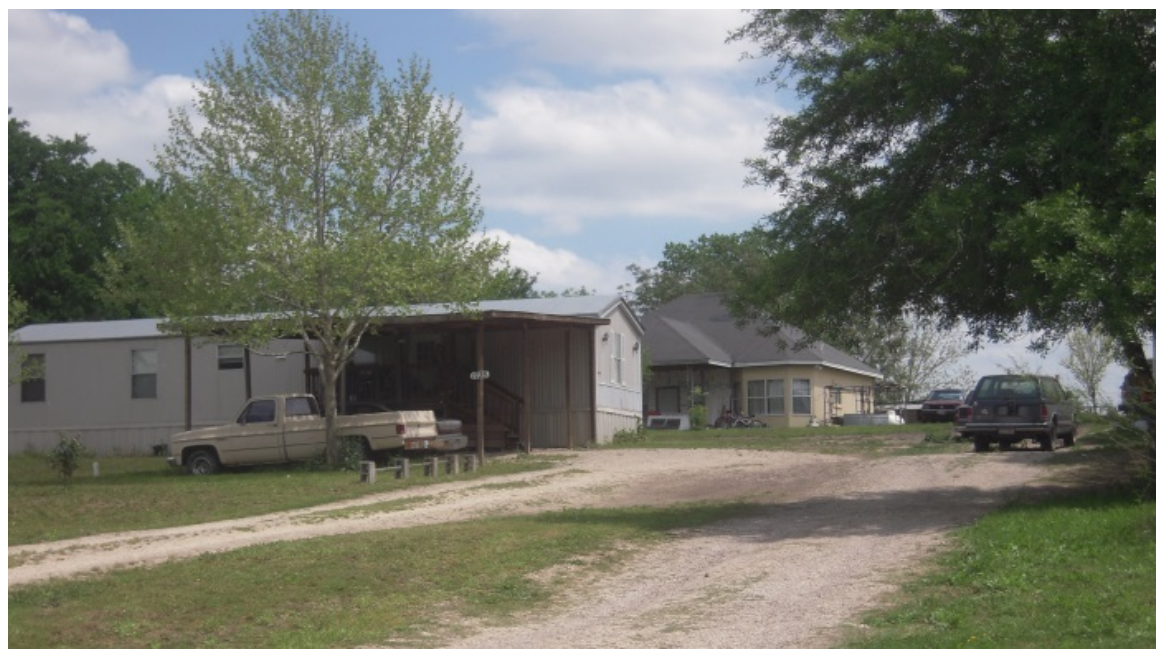

Figure 4. Two homes on site (probably related households). Front is manufactured; rear is custom home (Rancho Vista). Author's photo (Ward).

although the wheels may be removed when placed on site. Generally they are supported on brick piers, and often have a "skirt" around the base to disguise the wheel base and to keep out pests (as in Figure 1). Older trailers/manufactured homes are easily distinguished by their shape and sometimes by their "snout-nosed" feature at one end (Figure 2). These older trailer homes often predate the 1986 HUD (US Dept. of Housing and Urban Development) codes for manufactured home production. Some of the doublewides (especially) are spacious and come in sections with a porch or front extension. More recent manufactured homes are built to higher code specifications and to higher energy efficiency.

The median age of the primary dwelling units was 22 years, indicating that many houses are relatively old and likely are in need of repair or "weatherization" modifications. Only $1 / 3$ of the homes are less than 15 years old. Further, $26 \%$ of homes are 30 years or older. One quarter of respondents $(25.6 \%)$ report the presence of additional units on lot used either by themselves or by members of their household. In addition, 39.5\% have extended or added to their primary housing unit, $2 / 5$ of which are trailers. Self-built extensions are especially common. Where they exist, most of the additional secondary home units on the lot have 1 - 2 usable rooms (77\%). Three-quarters of the respondents indicate that their addition or extension is for the purpose of sleeping or is the primary residence of a second household (usually a close relation).

As Table 1 indicates the most common power source is electricity, and mixed electric and propane (tanks). Eighty-six percent use electricity to heat water, although one-fifth have serious water heating issues. One-half of the homes have partial AC, and only a minority reported full AC (31\%). Many have a system of partial AC (a window unit in the bedroom for example Figure 1), and use ceiling or floor fans elsewhere. Just over one third reported problems with air conditioning, including the high costs. 


\section{Findings: Housing \& Health}

In an earlier study using this same dataset, two of Ward's (then) graduate students Esther Sullivan and Carlos Olmedo (2015), undertook a statistical analysis in order to explore the determinants of severity among some the aforementioned housing problems for the Redwood and Rancho Vista subdivisions. They used an ordered logit model in which housing quartiles became the dependent variable, and a series of independent variables to ascertain the level of association. In that study the independent variables were: household income, age of the dwelling unit, house value, constructions skills of a household member, wastewater problems, Air Condition (AC) problems, type of garbage collection service, and self-reported severe health or mobility problems. Their analysis shows that the number and extent of housing problems increased with age of the dwelling structure, household reporting of problems with the septic tank system and with the source of air cooling, and if the household had a member with health issues or disabilities. On the other hand, the number of housing problems was found to decline (negative coefficients) as the value of the home increased, and especially if a member of the household had previous construction experience that enabled them to more readily overcome structural and other physical dwelling problems.

The linkage between having a poorer air cooling and many other consequent problems was less easy to discern, but Sullivan and Olmedo (2015) argue that it seems likely to relate to inadequate insulation and the costs of having effective air conditioning, both of which are a surrogate for poor quality homes and fittings, and are likely to aggravate health problems associated with higher summer ambient temperatures and poor air quality. Their data are a starting point for the following analysis.

\subsection{Residents' Perceived Housing Problems}

Table 2 shows a general (aggregate) percentage index that accounts for how the 133 respondents rated the 24 housing dimensions and the top (most frequent) problem noted by residents was that doors do not close properly, thus creating drafts and security concerns. Seventy-two percent of respondents report this to be a constant or occasional problem. The second, third and fourth top problems are somewhat related-that the dwelling unit is too hot during the summer or too cold during the winter (64\%); that it is poorly insulated (62\%). Between $50 \%$ and $56 \%$ of the households rated the following housing dimensions as a constant or occasional problem of the dwelling units: pest infestation, septic tanks, bathroom venting, roof leaks, flooring, kitchen venting, foundation, windows not closing properly, and electrical wiring (Table 2).

Household quartiles were also constructed based upon the severity of problems recorded, and a total of $18 \%$ of households fell into the 1 st quartile, meaning that almost one in five homes identified extensive and serious housing problems since they ranked between 19 and 24 of the housing dimensions as a constant or occasional problem. Another 24\% (almost one in four) households fell 
Table 2. Comparison of the percent of respondents that answered "Constant or Occasional Problem" vs. "Satisfactory or Good, Not a Problem".

\begin{tabular}{|c|c|c|c|c|}
\hline & & $\begin{array}{c}\% \text { Constant or } \\
\text { Occasional Problem }\end{array}$ & $\begin{array}{c}\% \text { Satisfactory or } \\
\text { Good, Not a Problem }\end{array}$ & $\%$ Problem Index \\
\hline 1 & Doors do not shut properly $(\mathrm{N}=123)$ & $71.9^{* * *}$ & 24.2 & 47.7 \\
\hline 2 & Unit is too hot in summer $(\mathrm{N}=121)$ & $68.5^{* * *}$ & 29.0 & 39.5 \\
\hline 3 & Unit is too cold in winter $(\mathrm{N}=119)$ & $63.9^{* * *}$ & 33.6 & 30.3 \\
\hline 4 & Poor insulation $(\mathrm{N}=112)$ & $61.9^{* * *}$ & 33.0 & 28.9 \\
\hline 5 & Pest infestation $(\mathrm{N}=106)$ & $55.7^{* * *}$ & 36.5 & 19.2 \\
\hline 6 & Problems with septic tank $(N=115)$ & $55.0^{* * *}$ & 40.8 & 14.2 \\
\hline 7 & Poor venting from bathroom $(\mathrm{N}=114)$ & 53.8 & 42.0 & 11.8 \\
\hline 8 & Roof leaks $(\mathrm{N}=118)$ & 53.3 & 45.0 & 8.3 \\
\hline 9 & Poor flooring $(\mathrm{N}=109)$ & 52.6 & 42.9 & 9.7 \\
\hline 10 & Poor venting from kitchen $(\mathrm{N}=112)$ & 52.6 & 42.4 & 10.2 \\
\hline 11 & Unstable foundation $(\mathrm{N}=111)$ & 52.1 & 42.7 & 9.4 \\
\hline 12 & Windows do not close properly $(\mathrm{N}=117)$ & 51.7 & 45.9 & 5.8 \\
\hline 13 & Electrical wiring and/or outlets $(\mathrm{N}=114)$ & 50.8 & 45.7 & 5.1 \\
\hline 14 & Plumbing leaks $(N=106)$ & 48.6 & 46.8 & 1.8 \\
\hline 15 & Mold $(\mathrm{N}=109)$ & 47.0 & 46.1 & 0.9 \\
\hline 16 & Poor venting from toilets $(\mathrm{N}=114)$ & 46.5 & 50.0 & -3.5 \\
\hline 17 & Humidity/condensation problems $(\mathrm{N}=111)$ & 46.1 & 50.4 & -4.3 \\
\hline 18 & Lack of privacy (poor sound proofing) $(\mathrm{N}=115)$ & 45.2 & 49.6 & -4.4 \\
\hline 19 & Poor air quality $(\mathrm{N}=106)$ & 44.0 & 47.4 & -3.4 \\
\hline 20 & House shakes when wind blows $(\mathrm{N}=112)$ & 43.2 & 51.6 & -8.4 \\
\hline 21 & Steps to the front door $(\mathrm{N}=104)$ & $36.6^{* * *}$ & 56.2 & -19.6 \\
\hline 22 & Insufficient hot/warm water $(\mathrm{N}=103)$ & $30.9^{* * *}$ & 62.7 & -31.8 \\
\hline 23 & Missing shingles $(\mathrm{N}=74)$ & $27.8^{\star *}$ & 40.8 & -13.0 \\
\hline 24 & Inadequate number of electrical outlets $(\mathrm{N}=104)$ & $27.2^{* * *}$ & 66.7 & -39.5 \\
\hline
\end{tabular}

Note: Problem areas are ranked by “\% Constant or Occasional Problem.” ${ }^{* *} p<0.01,{ }^{* *} p<0.05$.

within the 2nd quartile with substantial housing problems. Combined, this translates into two out of five homes (42\%) reporting substantial to extensive housing troubles related to their dwelling structures. Quartiles 3 and 4 reported "modest problems" (21.4\%) and few housing problems (36.4\%) respectively.

\subsection{Health Problems and Disabilities in Relation to the Dwelling Unit}

Returning to the present discussion of how housing conditions may intersect with health and wellbeing, our data show that more than half of the surveyed population (57\%) indicated that they have at least one member of their house- 
hold with some sort of severe health problem or disability. Of these the most frequently reported health problem is diabetes; $29 \%$ of the population reporting that a member of their household was afflicted by diabetes, which as H-EPESE data described earlier, is especially common among elderly Hispanics. While our data point statistic is striking in itself, it is almost certainly an underrepresentation of the incidence of diabetes within the two communities. Because residents were only asked if they or a member of their household was affected, it almost certainly undercounts the true number of total members of the household with diabetes. Oftentimes respondents answered "yes" (that someone in their household is affected) and then listed that both they and their spouse or a parent suffered, or that diabetes was an issue for several household members. It is clear that diabetes is a significant health problem in these communities and is closely associated with very-low reported incomes and high poverty levels of this particular population-both factors have been shown to contribute to diabetes (Black, 2002; Chaufan, Davis, \& Constantino, 2011).

The next most reported category for health and illness was the "other" category (25\%) which mostly related to cardiovascular disease or orthopedic problems (e.g., issues with back or bone joints). There were several other health problems that affect at least one member in about $15 \%$ of the households: poor mobility (15\%), asthma or respiratory problems (16.5\%), and migraines or headaches (14\%).

\subsection{The Links between Housing Problems and Health Outcomes}

No differences were observed between manufactured-vs-non-manufactured homes and the rate of reporting health problems. That said, when we asked the residents themselves how the aforementioned health and mobility issues were affected by their housing situations, many listed difficulties of getting into and around their homes (especially those with limited mobility), and generalized resulting stress. By their very nature manufactured homes are raised on a wheelbase and have several steps to enter the dwelling making access difficult for the mobility impaired. Even in homes on a slab, self-building and room extensions over time often make for irregular internal floor levels which inhibit mobility and pose higher risk of tripping on uneven surfaces. This is especially the case where dwellings are hybrid structures, commonly comprising both a trailer home and self-help extension(s) (Figures in Appendix A).

However, the housing condition that respondents cited as most often contributing to illness and poor health was poor indoor air quality which includes presence of mold, noxious odors, humidity, dust, and poor air circulation generally. This response is noteworthy given a growing body of research that links health outcomes such as asthma and lung cancer to the quality of indoor home environments. Americans tend to spend between $80 \%-90 \%$ of their time indoors, and children and the elderly especially spend a disproportionate amount of time indoors. However, as the US Environmental Protection Agency (2017) 
advises, indoor air is often more polluted than outdoor air.

The relationship between the condition of the physical house and negative health outcomes becomes clearer when one analyzes reported health problems within the groups that also report housing problems (compared to those that do not report housing problems) problems. Table 3 summarizes these findings by comparing those with no reported housing problems against those that report housing problems on the rate of reporting certain health issues. Although the sample size $(\mathrm{N})$ is not large, it is probably sufficient to allow us to draw some preliminary conclusions. The data show that those who report certain housing problems are more likely to report asthma or respiratory problems, migraines or headaches, and eye or nose irritation.

Some of the housing problems that seem more relevant for health issues are the presence of mold, as well as poor air quality, humidity and condensation and poor venting. For instance, $33 \%$ of residents who report by poor air quality, also report asthma or respiratory problems, compared to only $7.3 \%$ of those with no air quality problems (and this is a statistically significant relationship, according to the chi2 test). For mold, we see that $28.3 \%$ of those who report mold as report asthma or respiratory problems (compared to $12 \%$ of those with no mold issues).

Table 3. Households that answered they had "Constant" or "Occasional" Problems to selected housing dimensions and also Reported Specific Health Issues.

\begin{tabular}{|c|c|c|c|c|}
\hline & & $\begin{array}{c}\text { Asthma and } \\
\text { Respiratory } \\
\text { Problems }\end{array}$ & $\begin{array}{l}\text { Migraines } \\
\text { and } \\
\text { Headaches }\end{array}$ & $\begin{array}{l}\text { Eyes and } \\
\text { Nose } \\
\text { Irritation }\end{array}$ \\
\hline \multirow{2}{*}{ Poor air quality } & Yes $(N=51)$ & $33.3 \% * * *$ & $17.7 \%$ & $19.6 \% \%^{\star *}$ \\
\hline & No $(\mathrm{N}=55)$ & $7.3 \%$ & $10.9 \%$ & $5.6 \%$ \\
\hline \multirow{2}{*}{$\begin{array}{l}\text { Humidity \& } \\
\text { condensation }\end{array}$} & Yes $(\mathrm{N}=53)$ & $28.3 \%^{\star *}$ & $20.8 \%$ & $18.9 \%^{\star *}$ \\
\hline & No $(N=58)$ & $12.1 \%$ & $10.3 \%$ & $5.2 \%$ \\
\hline \multirow{2}{*}{ Mold } & Yes $(\mathrm{N}=55)$ & $32.7 \%^{* * *}$ & $23.6 \% * * *$ & $21.8 \%^{* * *}$ \\
\hline & No $(N=54)$ & $7.4 \%$ & $5.6 \%$ & $1.9 \%$ \\
\hline \multirow{2}{*}{$\begin{array}{c}\text { Poor venting from } \\
\text { kitchen }\end{array}$} & Yes $(N=62)$ & $27.4 \% * * *$ & $17.7 \%$ & $14.5 \%$ \\
\hline & No $(N=50)$ & $8 \%$ & $10 \%$ & $8 \%$ \\
\hline \multirow{2}{*}{$\begin{array}{c}\text { Poor venting from } \\
\text { bathrooms }\end{array}$} & Yes $(N=64)$ & $28.1 \%^{* \star *}$ & $17.2 \%$ & $15.6 \%^{* *}$ \\
\hline & No $(N=50)$ & $6 \%$ & $14 \%$ & $4 \%$ \\
\hline \multirow{2}{*}{$\begin{array}{l}\text { Poor venting from } \\
\text { toilets }\end{array}$} & Yes $(N=53)$ & $35.9 \% * * *$ & $18.9 \%$ & $18.9 \%^{\star *}$ \\
\hline & No $(N=57)$ & $5.3 \%$ & $12.3 \%$ & $5.3 \%$ \\
\hline \multirow{2}{*}{ Poor insulation } & Yes $(N=73)$ & $26 \% * * *$ & $17.8 \%$ & $13.7 \%$ \\
\hline & No $(N=39)$ & $51 \%$ & $10.3 \%$ & $5.1 \%$ \\
\hline $\begin{array}{l}\text { Doors do not shut } \\
\text { properly causing }\end{array}$ & Yes $(\mathrm{N}=92)$ & $20.7 \%$ & $18.5 \%$ & $14.1 \%^{\star *}$ \\
\hline drafts & No $(N=31)$ & $9.7 \%$ & $6.5 \%$ & $0 \%$ \\
\hline
\end{tabular}

${ }^{* *} p<0.01,{ }^{* *} p<0.05$. 
In the same line of argument, $23.6 \%$ of those who report mold also report migraines and headaches (compared to 5.6\% of those with no mold, and finally, $21.8 \%$ report eyes and nose irritation (versus $1.9 \%$ of those with no mold reported).

The analysis of housing conditions in Redwood and Rancho Vista informal subdivisions suggests that the number and extent of housing problems increases with age of the dwelling structure; households reporting of problems with the septic tank system and external evaporation leach-field; with the source of air cooling; and if the household has a member with health issues or disabilities. Furthermore, respondents said that difficulties of access into the home (steps, etc.), uneven internal surfaces, and especially poor indoor air quality were among the main elements affecting their health and mobility. In general, the housing mix (older trailers, new manufactured homes, and self-built units), and the physical nature and quality of the housing unit(s), appear most likely to exacerbate poor health through poor insulation from heat and cold, poor interior air quality, often inadequate bathroom facilities, and by mobility challenges that require ramps to the front door (Figure 5(a) \& Figure 5(b)). Moreover colonias and informal subdivisions present other disadvantages for health in general, and specifically for elderly populations. Given their peri-urban and rural location they are invariably isolated from care giving institutions such as health centers and hospitals, and the absence of public transportation to these neighborhoods, combined with the decline in private vehicle access and use among the elderly, often means greater dependence upon neighbors for transportation.

Dwelling structures and deteriorated housing conditions can produce poor health outcomes in general, and especially for elderly population for whom home improvement and upgrades are less likely and affordable. They are less able to undertake weatherization improvements (which reduce damp, improve insulation, etc.), resulting in exacerbation of their poor health status. Other health risks of these types of housing are small rooms, lack of privacy, and the already mentioned problems of inadequate heating and cooling. Such problems are lessened where the value of the home increases, and especially if a member of the household has previous construction experience, such that they can more readily overcome structural and other physical dwelling problems (Sullivan \& Olmedo, 2015; Sullivan \& Ward, 2012).

Elderly populations also have high exposure to hazards in the home (Carrillo et al., 2011) such as slippery surfaces, loose mats, lack of proximity of toilets to the bedroom, etc. That study also revealed that households with an elderly person present were often unprotected by smoke detectors, and that $25 \%$ of dwellings in such households were exposed to between four and six hazards.

\section{Conclusions: The Need for Further Research and the Health Paradox of Informal Housing}

Our research here, and that of many others before us, argues that elderly populations face a number of barriers to health care, including isolation, poverty, a lack 


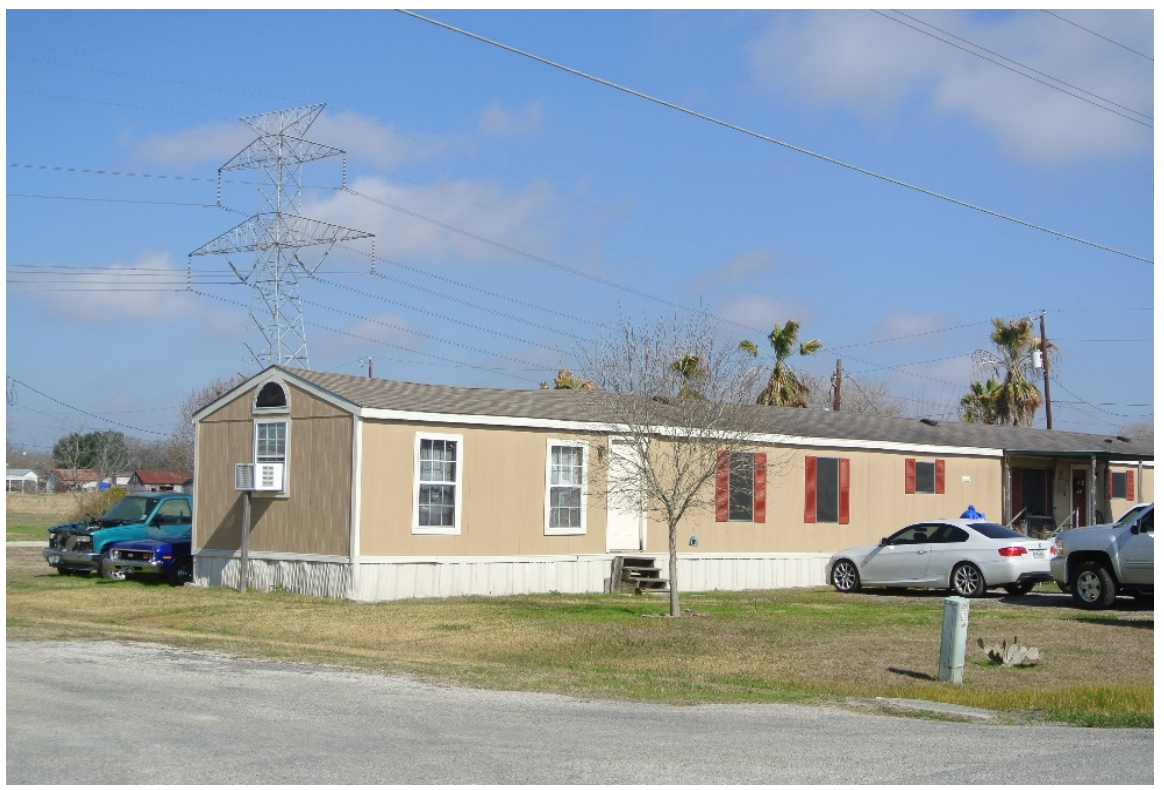

(a)

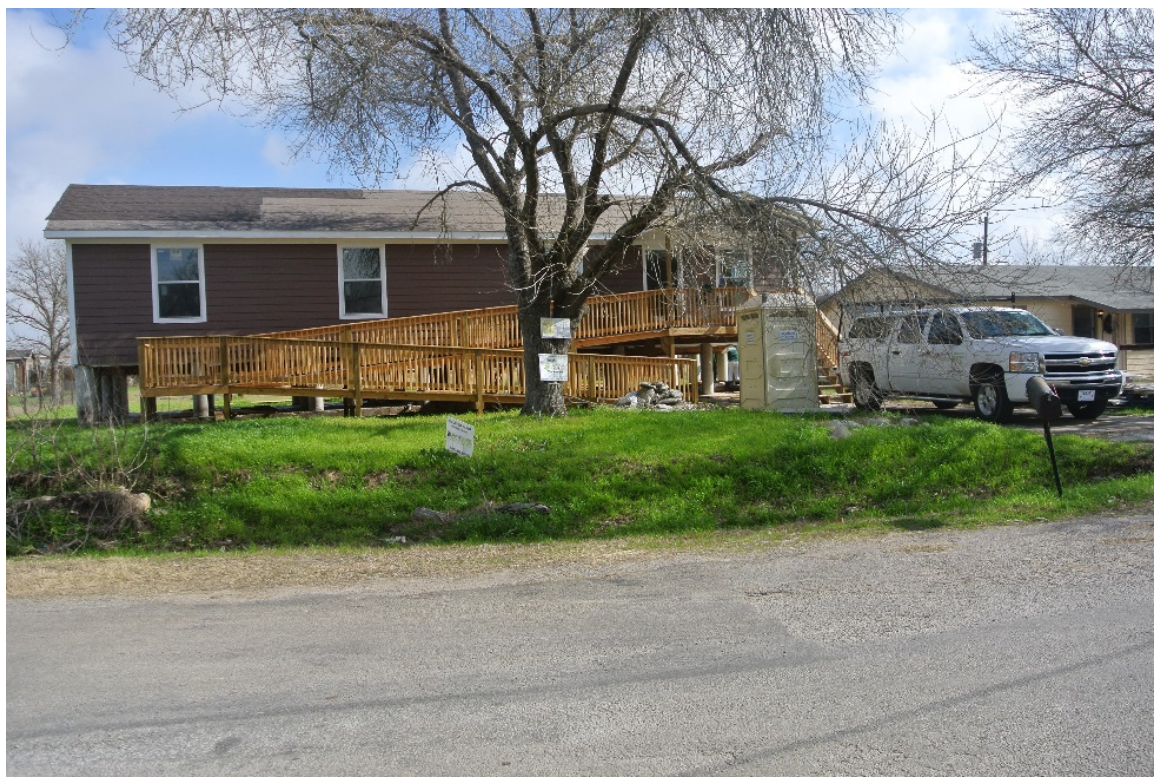

(b)

Figure 5. (a) \& (b) Dangers of steps up to entrance of manufactured home and ramps to provide safe access. (See also Figure A2) Author's photos (Ward).

of informal supports, and limited experience in accessing care. More specifically in relation to the micro dwelling environment, homes occupied by the elderly are often not equipped or adapted to their needs and in particular to the increasing fragility of their health as they get older. Moreover, house maintenance often becomes more difficult in later years. All of these elements make neighborhood quality and neighborhood services likely to have a greater impact on elderly residents' control of their environment and, hence, on their satisfaction.

There is an urgent need to think creatively about how space and context shape 
wellbeing and health among the elderly along a number of fronts: neighborhood, social capital, access, transportation, density, social interaction patterns, and other opportunities that reduce isolation and anomie. Therefore, as societies age there is a growing imperative to think about, and to provide for, appropriate residential environments that can accommodate the specific needs of the elderly. And yet there are relatively few major studies that seek to explore in detail how the physical structure and access of different dwelling environments intersect with health and morbidity outcomes. In large part this is because major social surveys such as the European Social Survey, the US Census, and the H-EPESE panels surveys mentioned earlier, rarely gather (any or) adequate data about the dwelling environment that could be linked to epidemiological or health outcomes. In these and other cases, therefore, there is an urgent need to build into major surveys a battery of questions relating to the dwelling environment, or to oversample these datasets with specific surveys of housing types, physical dwelling conditions, household structure and organization, and relational data such as access to local services, kin and other supportive social networks, etc.

Our study of two informal colonia-type settlements in Central Texas began with the proposition that the particular dwelling environments that we explored would be associated with certain health and morbidity outcomes, especially among elderly Hispanic resident home owners. As we outlined at the outset, various elements could be expected to come into play: the integrity of the physical structure itself; the capacity to control the internal climate; the levels of risk associated with exposure to disease, poor air quality, internal hazards; ease of access to the dwelling and safe mobility within it; and a positive neighborhood environment that enhances social interaction, daily observation of single of frail individual members of the community, and access to shopping facilities and to health and community services.

Albeit on a limited scale, prima facie our study shows how housing quality and structure may be important factors in shaping, or aggravating, poor health outcomes among residents. Inadequate insulation, ill-fitting doors and windows, the inability of many poor households to adequately control dwelling cooling or heating, poor indoor air quality appear to be associated with asthma, allergies, and "other" conditions such arthritis, bone pain, heart conditions, etc. The higher prevalence of diabetes among Hispanic elderly in our sample exacerbates some of these conditions. Uneven floors and difficulties of access also inhibit mobility and heighten risk of falls. As one would expect, such health outcomes and accidents are higher in older dwelling units. Future research should aim to undertake systematic data collection through surveys of health and morbidity patterns across a variety of dwelling environments (owned, rented and shared), ideally tied to large-scale studies such as those cited above, which would allow for more quantitative analysis and modeling.

In the same vein, we need to know much more about how the micro-spatial environment of home and yard/lot may offer opportunities for household ex- 
pansion across the life course, and especially for accommodating elderly parent(s) alongside adult children or other close kin-as described in this paper. Recent research in the US shows that informal housing arrangements are an increasingly common feature in high land value inner cities, and which in the past, have been most frequently associated with cities in less developed countries (Ward, 2012). Indeed, informality of housing arrangements is increasingly recognized in cities across the US (Durst \& Wegmann, 2017; Harris, 2017; Mukhija \& Loukatou-Sideris, 2014). It is often intrinsically desirable to have elderly relations living independently but close-up to their adult children, and such arrangements may be more pressing among low-income Hispanic households who are often unable to afford the costs of formal residential care. For them, formal and affordable residential care facilities are likely to be limited to Medicaid access (at best), and even in the US these opportunities are often poorly located and culturally alienating. Therefore, for those not eligible or unable to leverage formal residential care, ageing in place is likely to occur in single family homes prone to deterioration and poor maintenance, or in a rental apartments, or by doubling-up with adult children and their families.

For the elderly, place matters at the community level, especially given that these older established neighborhoods are themselves often subject to demographic and tenure-mix change, recasting the nature of social networks in which long established elderly residents are embedded, and reducing the provision and accessibility to key services and shopping opportunities.

And yet to date there is relatively little research and understanding of the relationship between housing structure and household organization. Prosper (2004), provides evidence that, in addition to the two usual types of residential care facilities (planned senior housing and single-family homes), public or private subsidized multifamily residences increasingly accommodate a growing population of elderly residents, the large proportion of which remain living there until they die or incur severe impairment. A feature of multifamily housing is that it is more likely to accommodate a mix of age groups, and thereby generates greater diversity and social mixing that may be conducive to wellbeing as well as to housing and community satisfaction. However, unlike senior housing, the physical design, location, staffing, services, and operating philosophy of multifamily housing are often not designed to meet the specific needs of ageing tenants, such that it is important that multifamily housing managers seek to balance the needs, lifestyles and expectations of these different constituencies.

\section{Final Reflections: A Paradox for the Elderly Who Live in Colonias and Informal Homestead Subdivisions?}

In the case of the two low income self-help dwelling environments in Central Texas described here, and for the many other colonia and informal homestead subdivisions about which we are all too often largely unaware, one sees an apparent paradox of low-income residential environments and responses that are 
both positive and negative for elderly populations who are ageing in place. On the one hand, self-help housing offers a means through which low-income elderly home owners may continue to live in their home, often living in close proximity to adult children, or be accommodated in the same residential space as their adult children. For the elderly with limited mobility, and for those suffering from Alzheimer's or late onset dementia, these large lots and informal neighborhoods provide relatively safe and caring environments (Ward, 2007). The large one-half to one-acre sized lots provide ample space to extend the dwelling horizontally, either contiguous to the main dwelling, or apart from it in separate units. The ample yard space, the porch and verandah areas that many add to the dwelling offer conducive and largely safe spaces in which elderly can relax, see, and be seen, and engage with their family and neighbors. The flexibility and relative affordability of self-building and self-managed housing practices, and the possibility for household extension and lot sharing, especially among Mexican-origin populations, combine to provide a culturally sensitive and meaningful housing alternative to that of formal care, even where the latter is available and affordable (rarely the case).

On the other hand, there is a downside. The actual structures themselves are often dilapidated and in acute need of maintenance and improvement; they have poorly insulation, and are inefficient in terms of energy usage, with poor internal climate control and regulation. Fuel poverty (Olmedo, 2014) increases the dangers of maintaining the home adequately heated or cooled such that damp and cold exacerbates several chronic illnesses such as those described above. Moreover, the structures themselves are often not conducive to physical mobility both outside and within the home, exposing residents to additional risks of slips and falls.

Another paradox is that despite the relative safety of living in a small community where neighbors can monitor each other, the low-density rural location means that there is lack of public transportation, such that that the elderly often find themselves isolated-both from their actual neighbors as well as from access to health care and other social service facilities. While close kin (adult children usually), often live close by, unless they share the home/lot or live next door, their elderly parents and kinsfolk are likely to remain highly dependent upon informal help from other community members to give them a ride to the doctors, for essential shopping and provisioning or for regular daily social contact.

Lot sharing between elderly parents and children can evolve in a number of ways. Where an adult child has acquired a lot upon which s/he is living and raising their own family, then if and when it becomes necessary that family may invite one or both parents to join them and live on site. This may be increasingly common in the next one or two decades, as the first generation of migrants from Mexico and elsewhere enter old age and rely on their children, or in some cases ageing parents are brought from Mexico under permitted family reunification visa programs. Another route to sharing in self-help colonia type settlements is 
where the pioneer householders age in place, and offer to share their homes with their adult children and families, one or other of whom ultimately becomes the primary caregiver. These informal settlements provide safe, viable, and in many cases highly rational and culturally sensitive living environment for low-income elderly populations, especially Mexican-origin Hispanics. Moreover, sharing the home with able-bodied, income earning and healthier household members, is likely to mitigate at least some of the negative effects associated with single family residence such as inadequate interior heating or cooling, poor air quality etc., incapacity to maintain and make repairs, as well as help to enhance physical mobility to enter (steps, ramps, etc.), as well as movement and safety within the dwelling unit(s). In short, informal housing and extended household arrangements can work and offer functional workarounds to poverty and for the elderly.

\section{Acknowledgements}

Funding for this study came from Dr. Ward's professorial chair (The C.B. Smith Sr. Centennial Chair in US-Mexico Relations, \#4 \& \#1) in the College of Liberal Arts, UT-Austin. Funds for publication in open access came from the same source (Chair \#1).

\section{Author Contributions}

P.W conceived and designed the study and directed the survey and fieldwork; F.B. undertook the primary literature review of housing and health; P.W and F.B shared the writing of the paper

\section{Conflicts of Interest}

The authors declare no conflict of interest. The founding sponsors had no role in the design of the study; in the collection, analyses, or interpretation of data; in the writing of the manuscript, and in the decision to publish the results.

\section{Supplementary Materials}

As stated in the paper, the original report, methodology and redacted database are publicly available at

https://www.lahn.utexas.org/Texas\%20 Colonias/Texas Colonias2.html.

\section{References}

Altergott, K. (1988). Social Action and Interaction in Later Life: Aging in the United States. In K. Altergott (Ed.), Daily Life in Later Life: Comparative Perspectives (pp. 117-146). Thousand Oaks, CA: Sage Publications.

Anders, R. L., Olson, T., Robinson, K., Wiebe, J., DiGregorio, R., Guillermina, M., Albrechtsen, J., Bean, N. H., \& Ortiz, M. (2010). A Health Survey of a Colonia Located on the US/Mexico Border. Journal of Immigrant and Minority Health, 12, 361-369. https://doi.org/10.1007/s10903-008-9186-7

Anders, R. L., Olson, T., Wiebe, J., Bean, N. H., DiGregorio, R., Guillermina, M., \& Ortiz, 
M. (2008). Diabetes Prevalence and Treatment Adherence in Residents Living in a Colonia Located on the West Texas, USA/Mexico Border. Nursing \& Health Sciences, 10, 195-202. https://doi.org/10.1111/j.1442-2018.2008.00397.x

Angel, R. J., Angel, J. L., \& Hill, T. D. (2008). A Comparison of the Health and Older Hispanics in the United States and Mexico: Methodological Challenges. Journal of Aging and Health, 20, 3-31. https://doi.org/10.1177/0898264307309924

Black, S. A. (2002). Diabetes, Diversity, and Disparity: What Do We Do with the Evidence? American Journal of Public Health, 92, 543-548.

http://www.ncbi.nlm.nih.gov/pmc/articles/PMC1447113/ https://doi.org/10.2105/AJPH.92.4.543

Blane, D., Mitchell, R., \& Bartley, M. (2000). The "Inverse Housing Law" and Respiratory Health. Journal of Epidemiology and Community Health, 54, 745-749. https://doi.org/10.1136/jech.54.10.745

Carrillo, C., Mier, N., Seol, Y.-H., Villarreal, E., Garza, N., \& Zuniga, M. A. (2011). Home Hazards Assessment among Elderly in South Texas Colonias. Texas Public Health Journal, 63, 14-17.

Chaufan, C., Davis, M., \& Constantino, S. (2011). The Twin Epidemics of Poverty and Diabetes: Understanding Diabetes Disparities in a Low-Income Latino and Immigrant Neighborhood. Journal of Community Health, 36, 1032-1043.

https://doi.org/10.1007/s10900-011-9406-2

Chipperfield, J. G. (1993). Perceived Barriers in Coping with Health Problems: A Twelve-Year Longitudinal Study of Survival among Elderly Individuals. Journal of Aging and Health, 5, 123-139. https://doi.org/10.1177/089826439300500106

Corburn, J., \& Riley, L. (Eds.) (2016). Slum Health: From the Cell to the Street. Oakland, California: University of California Press.

Davies, C. S., \& Holz, R. (1992). Settlement Evolution of the 'Colonias' along the US-Mexico Border: The Case of the Lower Rio Grande Valley of Texas. Habitat International, 16, 119-142. https://doi.org/10.1016/0197-3975(92)90056-5

Di Guiseppi, C., Jacobs, D. E., Phelan, K. J., Mickalide, A., \& Ormandy, D. (2010). Housing Interventions and Control of Injury-Related Structural Deficiencies: A Review of the Evidence. Journal of Public Health Management and Practice, 16, S34-S43. https://doi.org/10.1097/PHH.0b013e3181e28b10

Donelson, A. J., \& Esparza, A. X. (2010). The Colonias Reader: Economy, Housing, and Public Health in U.S.-Mexico Border Colonias. Tucson, AZ: The University of Arizona Press.

Durst, N. J. (2016). The Nature and Extent of Self-Help Housing in Texas: From Colonias to Model Subdivisions. Journal of Planning Education and Research, 36, 145-157. https://doi.org/10.1177/0739456X15612199

Durst, N. J. (2017). Residential Segregation at America's Urban Fringe. Unpublished PhD Dissertation, LBJ School of Public Policy, University of Texas at Austin.

Durst, N. J., \& Ward, P. M. (2014). Measuring Self-Help Home Improvements in Texas Colonias: A Ten Year "Snapshot" Study. Urban Studies, 51, 2143-2159. https://doi.org/10.1177/0042098013506062

Durst, N. J., \& Ward, P. M. (2016). Colonia Housing Conditions in Model Subdivisions: A Déjà Vu for Policy Makers. Housing Policy Debate, 26, 316-333. https://doi.org/10.1080/10511482.2015.1068826

Durst, N. J., \& Zhang, W. (2013). Health Risks and Disparities in Texas Colonias: Policy Analysis and Potential Solutions. Unpublished Paper. 
Durst, N., \& Wegmann, J. (2017). Informal Housing in the United States. International Journal of Urban and Regional Research, 41, 282-297.

https://doi.org/10.1111/1468-2427.12444

Evans, J., Hyndman, S., Stewart-Brown, S., Smith, D., \& Petersen, S. (2000). An Epidemiological Study of the Relative Importance of Damp Housing in Relation to Adult Health. Journal of Epidemiology and Community Health, 54, 677-686. https://doi.org/10.1136/jech.54.9.677

Gaymu, J. (2003). The Housing Conditions of Elderly People. Genus, 59, 201-226.

Gilbert, A. (1999). A Home Is Forever? Residential Mobility and Homeownership in Self Help Settlements. Environment and Planning. 31, 1073-1091. https://doi.org/10.1068/a311073

Gilbert, A., \& Ward, P. (1985). Housing, State and the Poor; Policy and Practice in Latin American Cities. Cambridge: Cambridge University Press. https://doi.org/10.1017/CBO9780511735363

Hall Ellenbecker, C., Byrne, K., O’Brien, E., \& Rogosta, C. (2002). Nursing Clinics in Elder Housing: Providing Access and Improving Health Care Outcomes. Journal of Community Health Nursing, 19, 7-15. https://doi.org/10.1207/S15327655JCHN1901_02

Harris, R. (2017). Modes of Informal Development: A Global Phenomenon. Journal of Planning Literature. https://doi.org/10.1177/0885412217737340

Hevia, S. (2013). Política Social de Vivienda en Chile y Envejecimiento: Avances y Desafíos. Rumbos TS, No. 7, 71-77.

Jacobs, D. E. (2011). Environmental Health Disparities in Housing. American Journal of Public Health, 101, S6-S8. https://doi.org/10.2105/AJPH.2010.300058

Jacobs, D. E., Brown, M. J., Baeder, A., Scalia Sucosky, M., Margolis, S., Hershovitz, J., Kolb, L., \& Morley, R. L. (2010). A Systematic Review of Housing Interventions and Health: Introduction, Methods, and Summary Findings. Journal of Public Health Management and Practice, September (Suppl), S3-S8. https://doi.org/10.1097/PHH.0b013e3181e31d09

James III, R. N. (2008). Residential Satisfaction of Elderly Tenants in Apartment Housing. Social Indicators Research, 89, 421-437. https://doi.org/10.1007/s11205-008-9241-8

Knab, B. R. (2016). Infectious Disease and the South Texas Colonias. Master of Science Thesis, The University of Texas at Austin.

Krieger, J. et al. (2010). Housing Interventions and Control of Asthma-Related Indoor Biologic Agents: A Review of the Evidence. Journal of Public Health Management and Practice, 16, S11-S20. https://doi.org/10.1097/PHH.0b013e3181ddcbd9

Krieger, J., \& Higgins, D. L. (2002). Housing and Health: Time Again for Public Health Action. American Journal of Public Health, Public Health Matters, 92, 758-768. https://doi.org/10.2105/AJPH.92.5.758

LBJ School of Public Affairs (2010) Housing Conditions, Sustainability and Self Help in Rancho Vista and Redwood Informal Homestead Subdivisions in Central Texas. Final Report and Database for the Community Residents and for the Community Development Clinic of the UT Law School.

http://www.lahn.utexas.org/Texas\%20 Colonias/Texas Colonias2.html

Mier, N., Ory, M. G., Zhan, D., Conklin, M., Sharkey, J. R., \& Burdine, J. N. (2008). Health-Related Quality of Life among Mexican American Living in Colonias at the Texas-México Border. Social Science \& Medicine, 66, 1760-1771.

https://doi.org/10.1016/j.socscimed.2007.12.017 
Miles, R., \& Jacobs, D. E. (2007) Future Directions in Housing and Public Health: Findings from Europe and Implications for Planners. Journal of the American Planning Association, 74, 77-89. https://doi.org/10.1080/01944360701784287

Mukhija, V. (2014). Outlaw In-Laws: Informal Second Units and the Stealth Reinvention of Single-Family Housing. In V. Mukhija, \& A. Loukaitou-Sideris (Eds.), The Informal American City: Beyond Taco Trucks and Day Labor (Urban and Industrial Environments) (pp. 39-58). Cambridge, Mass: MIT Press.

Mukhija, V., \& Loukatou-Sideris, A. (Eds.) (2014). The Informal American City: Beyond Taco Trucks and Day Labor. Cambridge, MA: MIT Press.

Oh, J. (2003). Social Bonds and the Migration Intentions of Elderly Urban Residents: The Mediating Effect of Residential Satisfaction. Population Research and Policy Review, 22, 127-146. https://doi.org/10.1023/A:1025067623305

Olmedo, C. (2014). Fuel Poverty and Housing Conditions in Texas Colonias. In Presentation at the 44th Urban Affairs Association Conference in San Antonio, Texas, March 20, 2014.

Olmedo, C., \& Ward, P. M. (2016). Model Subdivisions: The New Face of Developer Lot Sales for Low-Income Colonia-Type Housing in Texas. Land Use Policy, 52, 181-194. https://doi.org/10.1016/j.landusepol.2015.12.003

Prosper, V. (2004). Aging in Place in Multifamily Housing. Cityscape: A Journal of Policy Development and Research, 7, 81-106.

Sandel, M., Baeder, A., Bradman, A., Hughes, J., Mitchell, C., Shaughnessy, R., Takaro, T., \& Jacobs, D. (2010). Housing Interventions and Control of Health-Related Chemical Agents: A Review of the Evidence. Journal of Public Health Management and Practice, 16, S24-S33. https://doi.org/10.1097/PHH.0b013e3181e3cc2a

Sullivan, E., \& Olmedo, C. (2015). Informal Development in Low-Income Communities: Housing Conditions and Self-Help Strategies in Informal Subdivisions in Texas. Urban Studies, 52, 1037-1053. https://doi.org/10.1177/0042098014533733

Sullivan, E., \& Ward, P. M. (2012). Sustainable Housing Applications and Policies for Low-Income Self-Build and Housing Rehab. Habitat International, 36, 312-323. https://doi.org/10.1016/j.habitatint.2011.10.009

Sverdlik, A. (2011). Ill-Health and Poverty: A Literature Review on Health in Informal Settlements. Environment \& Urbanization, 23, 123-155. https://doi.org/10.1177/0956247811398604

Texas Attorney General (2014). Colonias Prevention: Historical Sketch of Texas Laws Related to Colonias Remediation and Prevention. https://www.texasattorneygeneral.gov/cpd/historical-laws-colonias

Thomson, H., Thomas, S., Sellstrom, E., \& Petticrew, M. (2009). The Health Impacts of Housing Improvement: A Systematic Review of Intervention Studies from 1887 to 2007. American Journal of Public Health, Research and Practice, 99, S681-S692. https://doi.org/10.2105/AJPH.2008.143909

TWDB (Texas Water Development Board) (1995). Water and Wastewater Needs of Texas Colonias: 1995 Update.

US Environmental Protection Agency (2017). https://www.epa.gov/indoor-air-quality-iaq/inside-story-guide-indoor-air-quality

Varley, A. (2008). A Place Like This? Stories of Dementia, Home and the Self. Environment and Planning D: Society and Space, 26, 47-67. https://doi.org/10.1068/d3105

Ward, P. (2016). The Reproduction of Informality in Low-Income Self-Help Housing 
Communities. In V. Mukhija, \& A. Loukaitou-Sideris (Eds.), The Informal American City: Beyond Taco Trucks and Day Labor (Urban and Industrial Environments). Cambridge, MA: MIT Press.

Ward, P. M. (1999). Colonias and Public Policy in Texas and Mexico: Urbanization by Stealth. Austin, Texas: University of Texas Press.

Ward, P. M. (2007). Colonias, Informal Homestead Subdivisions, and Self-Help Care for the Elderly among Mexican Populations in the United States. In J. L. Angel, \& K. E. Whitfield (Eds.), The Health of Aging Hispanics (pp. 141-162). New York: Springer. https://doi.org/10.1007/978-0-387-47208-9_11

Ward, P. M. (2012). A Patrimony for the Children: Low-Income Homeownership and Housing (im)Mobility in Latin American Cities. Annals of the Association of American Geographers, 102, 1489-1510. https://doi.org/10.1080/00045608.2011.628260

Ward, P. M., \& Peters, P. A. (2007). Self-Help Housing and Informal Homesteading in Peri-Urban America: Settlement Identification Using Digital Imagery and GIS. Habitat International, 31, 205-218. https://doi.org/10.1016/j.habitatint.2007.02.001

Ward, P. M., Jiménez, E., \& Di Virgilio, M. (2014) Intensive Case Study Methodology for the Analysis of Self-Help Housing Consolidation, Household Organization and Family Mobility. Current Urban Studies, 2, 88-104. https://doi.org/10.4236/cus.2014.22010

Ward, P., \& Carew, J. (2001). Tracking Absentee Lot Owners in Texas Colonias. A Methodology. Journal of Land Use Policy, 18, 73-86.

Way, H. K. (2010). Informal Homeownership in the United States and the Law. Saint Louis University Public Law Review, 29, 113-192.

Wegmann, J. (2015). Research Notes: The Hidden Cityscapes of Informal Housing in Suburban Los Angeles and the Paradox of Horizontal Density. Buildings \& Landscapes, 22, 89-110. https://doi.org/10.5749/buildland.22.2.0089

Wiese, A. (2005). Places of Their Own: African American Suburbanization in the Twentieth Century. Chicago, IL: University of Chicago Press.

Wilson, R., \& Menzies, P. (1997). The Colonias Water Bill: Communities Demanding Change. In R. Wilson (Ed.), Public Policy and Community: Activism in Governance in Texas (pp. 229-274). Austin, Texas: University of Texas Press.

World Health Organization Europe (2005). Is Housing Improvement a Potential Health Improvement Strategy? Health Evidence Network: Evidence for Decision-Makers. 


\section{Appendix A. Additional Photos of Housing Conditions in Informal Subdivisions}

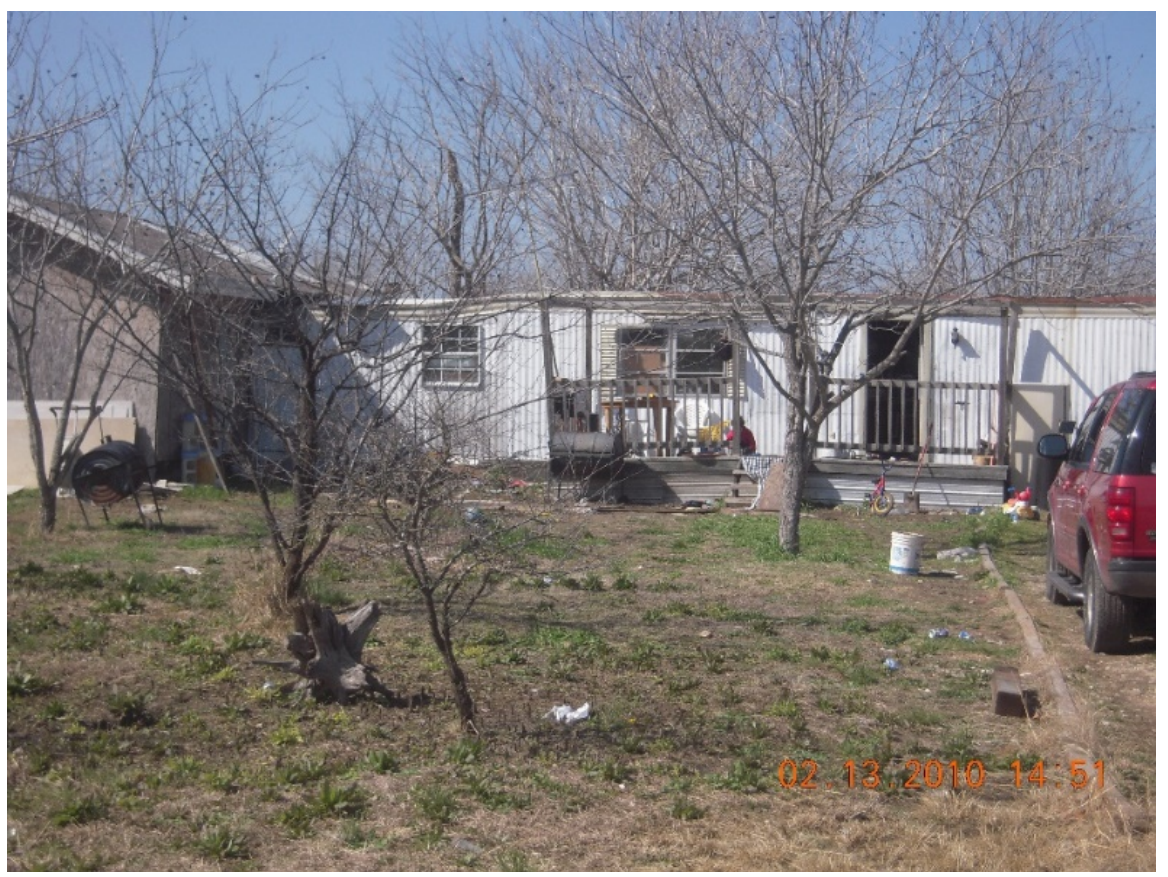

Figure A1. Dilapidated manufactured (trailer) home tied into a self-built (unfinished) dwelling unit (on left). Typical yard in winter. Author's photo (Ward).

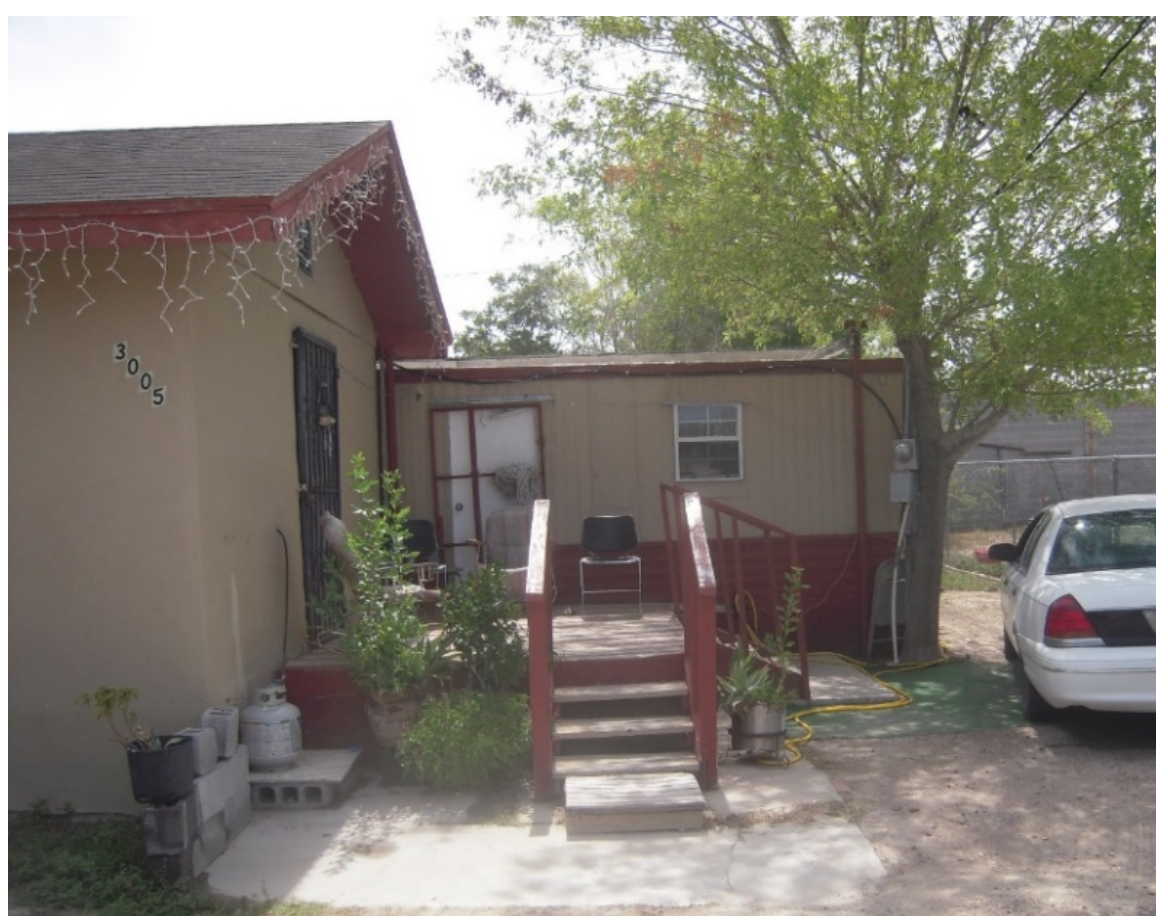

Figure A2. Hybrid dwelling structure comprising manufactured (trailer) home tied into a later self-built dwelling unit (on left). Author's photo (Ward). 


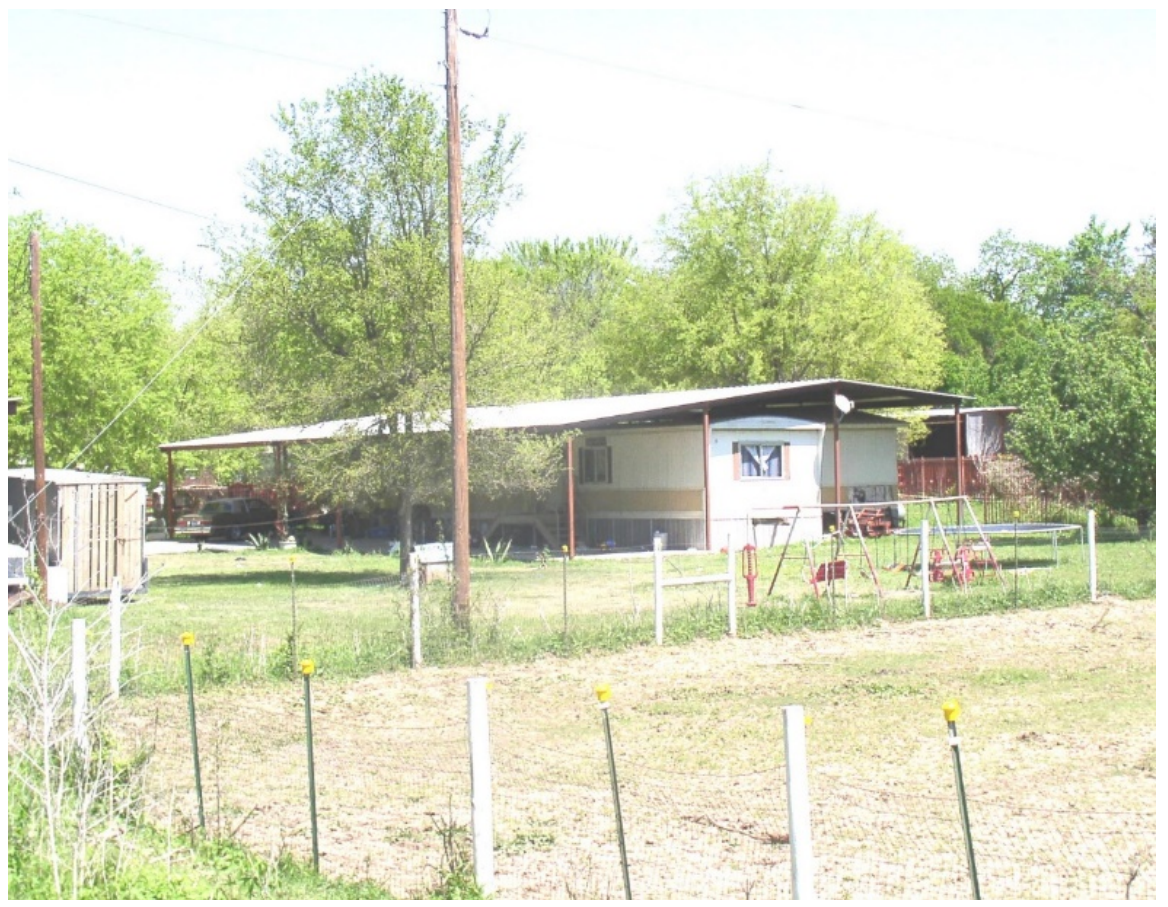

Figure A3. Manufactured home with rear extension; shading roof and large amenity lot (neighbors' paddock at front). Author's photo (Ward).

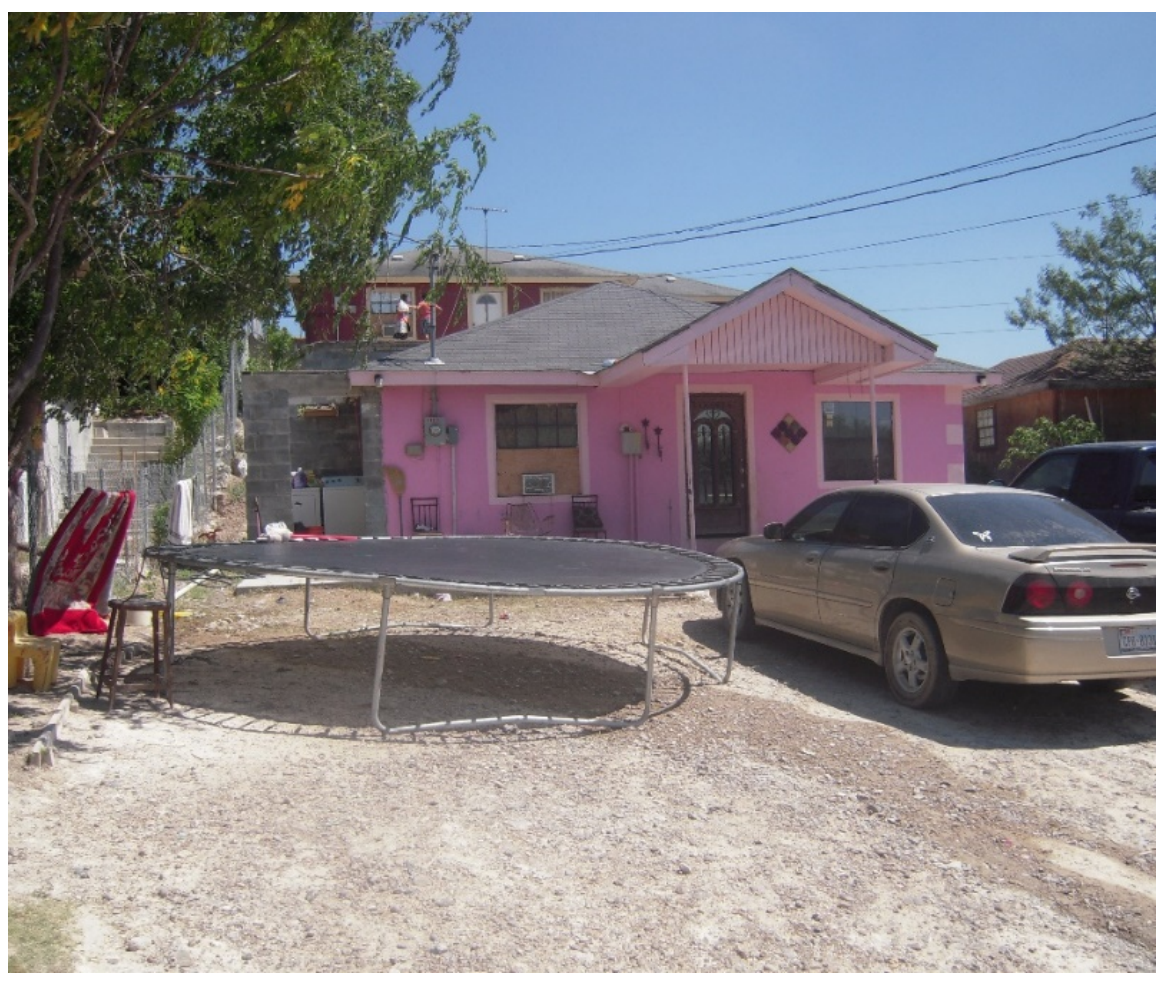

Figure A4. Shared lot with two self-built homes. Upper level is elderly parental home (red) and lower level daughter's family home (pink). Steps at side (invisible in photo) are steep and have hazardous unprotected drop on one side. (The two households plan on flipping their residence as the parents get older and struggle with mobility.) Author's photo (Ward). 